\title{
Does a Ban on Informal Health Providers Save Lives?
}

\section{Evidence from Malawi}

Susan Godlonton and Edward N. Okeke

RAND Labor \& Population

WR-1073-1

June 2015

This paper series made possible by the NIA funded RAND Center for the Study of Aging (P3OAG012815) and the NICHD funded RAND Population Research Center (R24HD050906).

RAND working papers are intended to share researchers' latest findings and to solicit informal peer review. They have been approved for circulation by RAND Labor and Population but have not been formally edited or peer reviewed. Unless otherwise indicated, working papers can be quoted and cited without permission of the author, provided the source is clearly referred to as a working paper. RAND's publications do not necessarily reflect the opinions of its research clients and sponsors. RAND® is a registered trademark. 


\title{
Does a ban on informal health providers save lives? Evidence from Malawi
}

\author{
Susan Godlonton* $\quad$ Edward N. Okeke ${ }^{\dagger}$
}

\begin{abstract}
Informal health providers ranging from drug vendors to traditional healers account for a large fraction of health care provision in developing countries. They are, however, largely unlicensed and unregulated leading to concern that they provide ineffective and, in some cases, even harmful care. A new and controversial policy tool that has been proposed to alter household health seeking behavior is an outright ban on these informal providers. The theoretical effects of such a ban are ambiguous. In this paper, we study the effect of a ban on informal (traditional) birth attendants imposed by the Malawi government in 2007. To measure the effect of the ban, we use a difference-in-difference strategy exploiting variation across time and space in the intensity of exposure to the ban. Our most conservative estimates suggest that the ban decreased use of traditional attendants by about 15 percentage points. Approximately three quarters of this decline can be attributed to an increase in use of the formal sector and the remainder is accounted for by an increase in relative/friend-attended births. Despite the rather large shift from the informal to the formal sector, we do not find any evidence of a statistically significant reduction in newborn mortality on average. The results are robust to a triple difference specification using young children as a control group. We examine several explanations for this result and find evidence consistent with quality of formal care acting as a constraint on improvements in newborn health.
\end{abstract}

Key words: informal health providers; government bans; child mortality

JEL Codes: I12, I15, O15

\footnotetext{
${ }^{*}$ Department of Economics, Williams College and IFPRI.

${ }^{\dagger}$ Department of Economics, Sociology and Statistics, RAND. Corresponding author. Email: eokeke@rand.org We thank participants at the 2014 Northeast Universities Development Consortium Conference and the 2015 Oxford CSAE Center conference for their thoughtful comments. We are especially grateful to Amalavoyal Chari and Claude Setodji for helpful conversations and suggestions. All mistakes remain our own. Dr. Okeke acknowledges support from the Eunice Kennedy Shriver National Institute of Child Health \& Human Development through Grant No. HD075943.
} 


\section{Introduction}

Households in developing countries receive a large fraction of their health care services from informal health providers. These providers range from traditional healers and birth attendants to drug vendors and village doctors. ${ }^{1}$ Estimates suggests that the informal sector accounts for anywhere between 9 to $90 \%$ of all healthcare interactions (Sudhinaraset et al., 2013). Informal providers play a particularly important role in the maternal health sector in low-income countries, attending up to half of all home births in sub-Saharan Africa and up to 40 percent of all births in South Asia (Darmstadt et al., 2009). They may also provide services such as prenatal care and child circumcision (Ofili and Okojie, 2005). In general these informal (or traditional) birth attendants, as they are known, have little formal education and are often self-taught - in a study by Hussein and Mpembeni (2005), 78 percent of surveyed traditional attendants had no formal education, 63 percent had learnt their skills from a female relative while 25 percent were self-taught - and many believe that they contribute to high rates of maternal and newborn mortality in developing countries (Bergström and Goodburn, 2001; Starrs, 2006). ${ }^{2}$ Despite the best efforts of regulators to shift births into the formal sector, the use of these informal (or traditional) birth attendants has remained popular (Titaley et al., 2010).

A recent controversial policy to influence household health seeking behavior is the imposition of a ban on these informal attendants. The logic underlying this policy is two-fold: first, that restricting access to these informal attendants will cause women to switch to formal providers, and second, that higher quality care in the formal sector will lead to reductions in mortality. It is not a priori clear that either of these assumptions is necessarily true. Regarding the first, a ban might simply shift use of these attendants underground, ${ }^{3}$ or may force women, particularly those with limited access to formal sector providers, to give birth at home unassisted (Bisika, 2008). Either of these behavioral responses would mute the effect of the ban and might even perversely worsen outcomes. Regarding the second, there is emerging evidence that the quality of care provided by formal sector providers may not be much better than that provided by informal providers on average (Das et al.,

\footnotetext{
${ }^{1}$ There is no universally agreed upon classification for formal/informal health providers, so we follow the taxonomy used by Sudhinaraset et al. (2013). In general these are unlicensed, unregulated providers.

${ }^{2}$ Others have argued that these informal attendants are vital, and ensure access to at least some form of skilled care, particularly in rural areas where there is poor access to formal providers (Bisika, 2008).

${ }^{3}$ The potential for bans to lead to hidden use of the proscribed behavior has been highlighted in other studies (Cheng, 2012).
} 
2012). To the best of our knowledge, there are no existing empirical studies of the effect of banning the use of informal health providers.

In this paper we study the effects of a ban on informal birth attendants imposed by the Malawi government in 2007. We use data from the 2010 Malawi Demographic and Health Survey supplemented with a geocoded dataset of all health facilities in Malawi. To estimate the causal effect of the ban on outcomes, we make use of a difference-in-difference strategy that exploits variation across time and space in the intensity of exposure to the ban. We define high intensity of exposure areas as those with high (historical) prevalence rates of informal birth attendant use. We argue that such areas likely experienced greater enforcement. To establish the validity of our empirical strategy, we show that low and high-exposure areas experienced similar trends prior to introduction of the ban; we also show that the treatment variable, the interaction between exposure and the timing of the ban is unrelated to observable birth, maternal, and household characteristics.

To summarize our results, we find that the ban substantially reduced the use of informal birth attendants. Our most conservative estimates suggest that the use of informal attendants decreased by about 15 percentage points. Consistent with policy objectives, we find that majority of these births appear to appear to have shifted to the formal sector - formal-sector births increased by about 11 percentage points - with the remainder accounted for by a small increase in relative/friendattended births. Substitution to relative/friend-attended births is primarily among women with high travel costs to health facilities. We find no evidence of an increase in the likelihood of an unattended birth.

Next, we examine whether the increase in the use of formal sector care improved newborn health. Despite the large shift from the informal to the formal sector, we find little evidence of a decrease in newborn mortality, on average, either within the first week or the first month. In our preferred specification the coefficient is positive (though not statistically significant) and the associated confidence intervals suggest that we can rule out a decrease in early neonatal mortality greater than about 6 deaths per 1,000 live births (relative to a baseline of 23 deaths per 1,000). To account for the possibility of differential unobserved shocks to child mortality, we estimate triple difference models using young children (children 2-5 years old) as a within-area control group and obtain similar results.

To understand why the shift from the informal to the formal sector did not translate into 
reductions in newborn mortality we examine three possible explanations. First, we examine whether there might be offsetting effects from the (small) increase in relative/friend-attended births - if these births were more likely to result in a newborn death, this might offset any reduction in mortality from the increase in births attended by formal-sector providers. Second, we examine whether mothers induced by the ban to use formal care (the 'compliers') are low-risk women who would have a good outcome regardless of where they delivered. Lastly, we examine whether the lack of an effect is due to low average quality of care in the formal sector.

We do not find support for the first two explanations. Our results suggest that low average quality of formal sector care is why the increased use of formal sector care did not lead to a measurable decrease in newborn mortality on average. We show that only households with access to a high quality facility (defined as whether the nearest health facility was in the top quartile of the quality distribution) experienced a reduction in newborn mortality - about 1.3-1.4 percentage points within the first week, and 1.6-1.8 percentage points within the first month. The mortality coefficients for the other households are positive though not statistically significant. These results are robust to a quadruple difference specification using young children as a within-area control group. These results suggest significant distributional consequences from the imposition of the ban. In general, most women faced higher costs of health care with no return in terms of improved newborn outcomes (that are statistically significant). However, women with relatively good access to high quality care did benefit with respect to lower newborn mortality, suggesting this type of policy may exacerbate inequality in infant health outcomes.

This paper makes an important contribution to a growing literature that estimates the returns to care in the formal sector (Adhvaryu and Nyshadham, 2014; Mazumdar et al., 2011; Okeke and Chari, 2014). ${ }^{4}$ Despite the effectiveness of interventions designed to increase the use of formal sector care, evidence of significant health improvements, and in particular, reductions in mortality have been hard to come by. ${ }^{5}$ Our results are largely consistent with this literature but we advance the discussion by showing that low average quality of care in the formal sector may help to explain why increased use has not translated into significant improvements in health outcomes. This paper also

\footnotetext{
${ }^{4}$ There is a related US literature that estimates the marginal returns to health care. See for example Almond et al. (2010) and Almond and Doyle (2011).

${ }^{5}$ Adhvaryu and Nyshadham (2014), who find that care in the formal sector in Tanzania improves malaria and fever outcomes for children, is one of the exceptions.
} 
makes a contribution to the economic literature that studies how changes in access to providers affects health outcomes. ${ }^{6}$ Relative to this literature, we study how restrictions in access to informal providers - in this case informal birth attendants - affects health outcomes. Finally, we make a contribution to a literature that studies the welfare implications of government bans as a policy instrument to change health-related behavior. See for example Nandi and Deolalikar (2013) who study the effect of a law banning sex-selective abortions in India, and Adda and Cornaglia (2010) who study the effect of smoking bans.

The remainder of the paper is set out as follows: in Section 2 we provide a brief overview of delivery care in developing countries and child health, in Section 3 we discuss the institutional details of the ban in Malawi, in Section 4 we discuss the data, in Section 5 we discuss our empirical strategy, in Section 6 we present the results, and in Section 7 we conclude.

\section{Delivery care and child health}

Nearly eight million children die every year before they turn five and reducing these deaths is of considerable policy and economic interest (Rajaratnam et al., 2010). ${ }^{7}$ A major target of policy efforts is newborn mortality because it constitutes 40 percent of all under-five child deaths. According to the latest estimates, about 3 million infants die annually within a month of being born. Deaths are clustered around the time of delivery, with $25 \%$ of deaths occurring on the first day, and $75 \%$ occuring within the first week. ${ }^{8}$ Leading causes of newborn deaths include complications of prematurity, birth asphyxia, ${ }^{9}$ and infections. For many of these, timely intervention by skilled providers is essential for survival, and it has been estimated that skilled care during childbirth can prevent up to $50 \%$ of newborn deaths (Bhutta et al., 2014). However, nearly 60 million births worldwide take place outside of formal facilities (Darmstadt et al., 2009). In sub-Saharan Africa and South Asia, the two regions that account for most newborn deaths, nearly $60 \%$ of all births take place at home (Montagu et al., 2011). About half of these births are attended by informal

\footnotetext{
${ }^{6}$ Examples of this literature include Buchmueller et al. (2006) who study the effect of hospital closures in California on adult mortality, and Valente (2014) who studies the effect of the opening of abortion centers on neonatal outcomes in Nepal.

${ }^{7}$ The fourth Millennium Development Goal, for example aims to reduce child deaths by 75 percent by 2015 .

${ }^{8}$ Newborn deaths are also clustered in certain parts of the world. More than $65 \%$ of all newborn deaths occur in the following countries: Afghanistan, Bangladesh, China, Democratic Republic of the Congo, Ethiopia, India, Indonesia, Nigeria, Pakistan, and Tanzania (Lawn et al., 2009).

${ }^{9}$ Deaths due to asphyxia are now classified as intrapartum-related neonatal deaths.
} 
(traditional) attendants. ${ }^{10}$

The literature has shown an inverse relationship between use of formal providers (typically doctors, nurses and midwives) and rates of newborn mortality. We illustrate this relationship in Figure 1 using 2010 World Bank data for 52 countries. ${ }^{11}$ This stylized relationship has motivated current policies that seek to shift births from the informal to the formal sector as a way to reduce newborn mortality. Several recent studies have however questioned the rationale behind these policies, finding no evidence that shifting births to the formal sector reduces mortality (see for example Okeke and Chari, 2014).

\section{The ban on informal attendants in Malawi}

Informal birth attendants have a long history in Malawi. In the 1980s the official government policy was to train and equip them with the proper skills (Chen et al., 2011), but this was discontinued in the 1990s as global health policy shifted towards emphasizing skilled birth attendance, a term largely synonymous with institutional births (World Health Organization, 1992). Many women however continued to use these informal providers. As of 2006, nearly one in five births in Malawi was attended by an informal birth attendant. ${ }^{12}$

In 2007 the Malawian government announced that informal birth attendants were no longer allowed to attend deliveries. This was in an attempt to reduce high rates of mortality and achieve Millennium Development Goal mortality targets. ${ }^{13}$ This policy was outlined in a report released in July 2007 and was implemented starting in October 2007 (Ministry of Health, 2007). The ban imposed substantial financial penalties on both the informal birth attendant and the mother. Typical fines ranged from three chickens to a goat (chickens cost between 150 and 300 Kwacha, while a goat can cost up to $1,500 \mathrm{Kwacha}) .{ }^{14}$ In Malawi, informal birth attendants charge around 200 Kwacha for a delivery (Kumar, 2007), while health facilities might charge anywhere from zero

\footnotetext{
${ }^{10}$ The World Health Organization defines a traditional birth attendant as a person who assists the mother during childbirth and who initially acquired her skills by delivering babies herself or through an apprenticeship to other traditional birth attendants (World Health Organization, 1992). Throughout the rest of this paper, when we use the term 'informal birth attendant' this is what we mean.

${ }^{11}$ Data is from the World Bank Health Nutrition and Population Statistics database.

${ }^{12}$ This fraction is much higher in other countries.

${ }^{13}$ In 2007, the maternal mortality ratio in Malawi was 807 per 100,000 live births, one of the highest in Sub-Saharan Africa; neonatal and infant mortality rates were also high at 33 and 72 per 1,000 live births respectively (National Statistical Office, Malawi and United Nations Children's Fund (UNICEF), 2008).

${ }^{14}$ In $2008 \$ 1=$ KW 140.
} 
to about 1,000 Kwacha depending on the type of facility (Levin et al., 2003). To help provide some context for these numbers, the per-capita gross national income for Malawi in 2008 was approximately US\$290 (World Bank, 2014). Though systematic data on enforcement is not available, since enforcement was largely left to the sub-district and village heads, there is some evidence that the ban was enforced. Several Malawian newspapers for example reported stories of women in rural areas walking long distances to get to the nearest maternity center, and in some cases giving birth along the way. ${ }^{15}$

Essentially the ban raised the cost of using an informal birth attendant, increasing the cost relative to the formal sector. Due to this change in relative prices, one would expect the demand for informal birth attendants to decrease. Available substitutes for an informal birth attendant include formal sector providers, other informal alternatives such as having a relative or friend present at the birth, or an unassisted birth. Given this set of choices, one might expect comparatively more women to switch to a formal sector provider after the ban, but the extent of the substitution would depend on the perceived quality differences (relative to the costs) among the available alternatives as well as budget constraints faced by the woman at the time of delivery.

The a priori effect of the ban on health outcomes is ambiguous. It would depend on the composition of women who were previously using informal birth attendants, the direction and extent of substitution, and the relative differences in marginal health products. If post-ban all informal sector births shifted to the formal sector, then assuming higher quality on average, mortality would almost certainly decline. If instead, women opted to stay home and deliver unassisted, then one might expect mortality to increase. Furthermore, mortality might increase because of the additional stress imposed on women attempting to reach formal health facilities during labor, or because informal attendants went underground and practiced in secret. In the latter case, mothers who experienced complications might be more reluctant to go to a formal health facility for fear of being penalized. Since theory does not yield a clear prediction, the mortality effects of a ban on informal birth attendants is an empirical question.

\footnotetext{
${ }^{15}$ A series of reports published in The Nation, a daily newspaper in Malawi, that depicted the hardships faced by pregnant women as a result of the ban is widely believed to have contributed to a lifting of the ban by the president in September 2010 (Young, 2010).
} 


\section{Data}

\subsection{Malawi Demographic and Health Survey}

Our primary dataset is the 2010 Malawi Demographic and Health Survey (MDHS). The MDHS sample uses a stratified, two-stage cluster design, with census enumeration areas being the sampling units for the first stage. The 2010 MDHS sample includes 849 clusters (or villages) - 158 in urban areas and 691 in rural areas. Within each selected household, women of reproductive age (15-49 years old), and household heads are interviewed. Women are asked about all births within the preceding five years. For each birth, respondents are asked to provide detailed information about the place of birth, whether there was an attendant present at the birth, the type of attendant (women are specifically asked whether the birth was attended by a traditional birth attendant), and whether the child is alive or dead. For the subset of children who have died, detailed information is collected about age at death (to the nearest day for children who died in the first month after delivery). Data on mortality is collected for all births, not just births within the last 5 years.

Given the retrospective nature of the data, measurement error is a valid consideration, particularly for infant deaths. We note however that recall error has generally been shown to not be an issue for live born children, with the exception of some age heaping for reported deaths (Beckett et al., 2001). For example, children who die on Day 27 may be reported by mothers as having died at one month. We account for this rounding error by defining deaths within the first month as a newborn death (even though the technical definition is deaths within 28 days). In our mortality analyses, we also restrict the sample to children born within the last 10 years to mitigate this issue. ${ }^{16}$

\subsection{Health Facility data}

The facility level dataset contains data on all health facilities (public and private) in Malawi and includes information about various services offered by the health facility. ${ }^{17}$ We drop facilities that do not offer maternity services leaving us with 517 health facilities across Malawi. The data is geocoded, allowing us to link the data to the DHS. ${ }^{18}$ For each facility, we have some data on facility

\footnotetext{
${ }^{16}$ As we will show later, the results are not sensitive to this restriction.

${ }^{17}$ This survey was conducted in 2003.

${ }^{18}$ In the DHS a GPS reading is taken for each cluster and readings are accurate to approximately 15-20 meters. To protect the identity of survey participants, GPS locations are randomly displaced. The measurement error introduced by this random displacement will tend to attenuate estimates.
} 
characteristics such as whether a trained provider is available at all hours, whether they have a laboratory, or provide blood transfusion services, and other services. We later use these measures to construct an index of quality.

\subsection{Descriptives}

Table 1 contains summary statistics. Panel A shows individual-level characteristics while Panel B shows birth-level characteristics. In Panel B, we present disaggregated results for births before and after the ban.

After dropping 287 observations belonging to non-resident household members, we have data on 13,564 women and 19,680 births; 10,341 in the post-ban period. The average age of women in the sample is 28 years. The majority (67 percent) have only completed some primary schooling. 86 percent are married or living with a partner, 85 percent live in a rural community, and only 8 percent have electricity in their dwelling. Before the ban, about 70 percent of births took place in the formal sector (defined as births in a government, private or mission-owned health facility), ${ }^{19}$ while informal birth attendants attended about 18 percent of all deliveries. After the ban the percentage of deliveries attended by a formal provider increased to 74 percent, while the percentage of births attended by informal birth attendants dropped to 11.5 percent. On average, 3.1 percent and 2.3 percent of newborns died within the first month and first week, respectively, before the ban was instituted. Both the probability of a newborn death within the first month and within the first week increase slightly in the post-period to 3.2 percent and 2.6 percent respectively.

\section{Empirical Strategy}

Our empirical approach is fairly straightforward. We implement a difference-in-difference estimation strategy that exploits variation across time and space in 'intensity of exposure' to the government ban. Our proxy for intensity of exposure is the village-level historical rate of informal birth attendant use. ${ }^{20}$ We assume a principal-agent framework in which the central government

\footnotetext{
${ }^{19} 31 \%$ of formal-sector births were in a government hospital, $48 \%$ were in a government health center, $19 \%$ were in a mission-owned health facility, and $2 \%$ were in a privately-owned facility. $13 \%$ of formal sector births were attended by a doctor/clinical officer, $82 \%$ were attended by a nurse/midwife and $4 \%$ were attended by a patient attendant.

${ }^{20}$ This strategy of defining exposure based on baseline levels has been used before in the literature. See for example Osili and Long (2008).
} 
wishes to reduce the average rate of informal birth attendant use - and hence introduces the ban - but enforcement is ceded to the subdistrict and village heads because they are better able to monitor behavior and ensure compliance. First, since the objective is to reduce the average, it is likely that village heads with high rates of use at baseline will face greater scrutiny/pressure to bring down their rates in order to be in compliance with the law. ${ }^{21}$ Village heads in such areas should therefore be more likely to exert effort to identify and penalize defaulters. Second, local leaders in such areas should be more likely to enforce because they directly benefit from fines collected rents are not remitted to the central government - suggesting that their incentives are properly aligned. Unfortunately, systematic enforcement data was not collected in Malawi so we are not able to conclusively prove this, but qualitative evidence gathered from interviews of knowledgeable Ministry of Health staff and village heads in Malawi conducted in September 2013 is consistent with this interpretation. Figure 2 provides descriptive supporting evidence for this claim. Areas with higher rates of baseline use see a much larger reduction after the ban is implemented relative to areas with lower rates of baseline use.

In the analyses that follow, we define a high-exposure village as one where baseline prevalence of informal attendant use exceeds the 75 th percentile. ${ }^{22}$ We chose this cutoff to balance two opposing considerations. First, we wanted to ensure that high-exposure corresponded to a meaningfully high fraction of informal attendant use, and second, we wanted to ensure a sufficient sample of 'treated' births (births in high-exposure villages). Raising the cutoff increases the first but decreases the second. The choice of the 75th percentile may seem somewhat arbitrary but we later show that the results are robust to the choice of cutoff. Our treatment variable is the interaction between the high-exposure variable and Post, a binary indicator for births that take place after the ban. The basic regression specification is as follows:

$Y_{i c d t}=\alpha_{1}+\alpha_{2}$ Post $_{t}+\delta$ HighExposure ${ }_{c}+\gamma$ HighExposure E $_{c} *$ Post $_{t}+X_{i c t} \beta+\eta_{d}+\tau_{t}+\epsilon_{i c d t}$

Even though most of our outcomes are binary, we prefer a linear probability model primarily because it allows for ease of interpretation of the coefficients on the interaction terms. With fixed effects logit

\footnotetext{
${ }^{21}$ We assume that the central government has leverage over the subdistrict and village heads and is able to punish those that do not comply.

${ }^{22}$ This translates to about $29 \%$ of births attended by an informal birth attendant. In Appendix Figure A.1, we graph the entire distribution.
} 
models, one cannot calculate marginal effects of independent variables without making arbitrary assumptions about the value of the fixed effects. We, however, confirm that the signs and significance of the relevant coefficients hold when using the conditional logit. $Y_{i c d t}$ denotes (i) the probability that child $i$ in cluster $c$ in district $d$ at time $t$ was delivered by an attendant in the informal or formalsector, and (ii) the probability that child $i$ in cluster $c$ in district $d$ born in time $t$ died within $X$ days of being born $(X=7,30)^{23}$. Post $_{t}$ is an indicator variable equal to 1 if a birth took place after the ban was introduced (Post $=1$ if the child was born after December 2007). HighExposure denotes a DHS cluster with a historical prevalence rate $\geq 75 t h$ percentile. $X_{i c t}$ is a vector of individual, household and village characteristics. $\eta_{d}$ are district fixed effects (in some specifications we replace $\eta_{d}$ with $\eta_{c}$ i.e., cluster fixed effects). $\tau_{t}$ are year $\mathrm{x}$ birth month dummies to capture time trends in a flexible way. In some specifications we relax the assumption of common time trends and allow time trends to vary by district. The inclusion of district-specific trends allows us to account for any unobserved time-varying shocks to aggregate demand or supply within a district. In all regressions, standard errors are clustered at the district level (there are 27 districts). Conditional on the validity of our identifying assumption, $\gamma$ identifies the causal effect of the ban. Next we discuss the validity of our empirical strategy.

\subsection{Validity of the empirical strategy}

The use of formal/informal birth attendants is unlikely to be random: places where women tend to use informal birth attendants are likely to have certain characteristics - as we show later, for example, high-exposure villages are more likely to be located further away from a health facility. It is important to highlight that identification in our models does not require that high and lowexposure villages be similar, only that trends be similar. In other words, we assume that trends in low-exposure areas represent a valid counterfactual for high-exposure areas in the absence of the treatment. While this is ultimately untestable, we can test whether trends in both areas were parallel prior to the introduction of the ban. In Table 2 we regress each outcome of interest on an interaction between a monthly time trend and an indicator for high-exposure using data from the pre-ban period. We see from Table 2 that we cannot reject the null of similar pre-trends for any of

\footnotetext{
${ }^{23}$ In our main specifications, we limit the definition of mortality to only include deaths of live births as reported by the mother. We later extend this definition to include stillbirths which we discuss in detail in Section 6.4.3.
} 
the outcomes. The coefficient on HighExposure $*$ Trend, is both small in absolute magnitude and statistically insignificant. $^{24}$

In Figure 3, we show how high and low-exposure areas are distributed across Malawi (green dots represent low-exposure villages while red dots represent high-exposure villages). In Table 3 we compare birth, maternal and household characteristics across high and low-exposure areas. We find that high- and low-exposure areas indeed have different characteristics: high exposure areas are poorer, more rural, and more likely to be located further away from a health facility. Low-exposure villages are more likely to be located in the northern region. ${ }^{25}$ Reassuringly, however, births and mothers in both areas look very similar. In Table 4 we show that while high exposure is correlated with observable characteristics, the treatment variable, the interaction between high-exposure and Post, is not, increasing confidence in the validity of our empirical strategy.

Our estimation strategy assumes that nothing changed differentially over time in the two areas that would have affected mortality. The fact that Table 4 shows no differential change over time in birth and household characteristics, helps to assuage concern about possibly unobserved shocks that might be correlated with child mortality since any such shocks, if significant, would plausibly alter birth/household characteristics. ${ }^{26}$ In the analyses that follow we estimate model specifications that allow for district-specific time trends, which would help to soak up any unobserved time-varying shocks across districts. Lastly, as an additional robustness exercise we estimate triple difference models where we compare changes in mortality among newborn infants (the 'treated' group) to changes in mortality among untreated young children (2-5 year olds) in high- vs. low-exposure areas. In this specification young children serve as a within-area control group allowing us to control for any unobserved differential shocks to child mortality. Both of these strategies account for natural disasters (e.g. floods or droughts) that might differentially affect low and high exposure communities over time, for example the Karonga earthquake in $2009 .^{27}$

\footnotetext{
${ }^{24}$ In addition, we examine data from the Integrated Household Survey, a nationally representative survey. Using the 1998 and 2004 waves we observe that trends in other dimensions, in general do not exhibit differential trends. The results are presented and discussed in Appendix A.

${ }^{25}$ The Northern region has higher education levels and much lower population density relative to the Central and Southern regions. We therefore check that our results are robust to excluding the North.

${ }^{26}$ To provide further supporting evidence we utilize the 2004 and 2010 waves of the Integrated Household Survey and observe that the interaction between high-exposure and Post, is not statistically significant, increasing confidence in the validity of our empirical strategy as it suggests that there is unlikely to be some factor correlated with high exposure driving the observed results. Further details are provided in Appendix A.

${ }^{27}$ We also check that the results are robust to excluding Karonga district from the analysis.
} 


\section{Results}

\subsection{What was the effect of the ban on the use of informal birth attendants?}

We begin by presenting descriptive evidence. In Figure 4, we plot trends in high- vs. lowexposure villages. The dotted line indicates the year in which the ban was introduced. The visual evidence is very striking: we see that following the introduction of the ban, the probability that a baby in a high exposure village was delivered by an informal attendant dropped by about 15 percentage points within a year (from $43 \%$ to $28 \%$ ). In contrast, the probability that a baby was delivered by an informal attendant remained unchanged in low-exposure villages over the same period. Important for our identification strategy, we see that pre-ban, the trends for both groups are parallel.

In Table 5 we present the difference-in-difference results. Column 1 shows the basic specification with district and year $\mathrm{x}$ month fixed effects. In Column 2 we include the following controls: an indicator for gender of the baby, an indicator for a multiple birth, birth order, dummies for mother's level of schooling, dummies for mother's age at birth, an indicator for women who are married or living with a partner, dummies for ethnicity and religion, dummies for the partner's educational attainment, distance to the nearest health facility, wealth quintile dummies, and a rural-urban indicator. ${ }^{28}$ In Column 3 we interact all the control variables with the Post indicator, in Column 4 we include district-specific time trends, and in Column 5, to account for 'floor' and 'ceiling' effects, we drop villages with baseline prevalence equal to 0 or 1 . Column 6 is identical to Column 3 except that district fixed effects have been replaced with cluster fixed effects.

We see that the imposition of the ban significantly reduced the use of informal birth attendants - by about 15 percentage points in our most conservative specification. The coefficients on the included control variables have the expected signs and magnitudes. Education has a strong negative and monotonic effect on the use of an informal birth attendant. We find a similar negative effect of household wealth: women in the richest wealth quintile are about 6 percentage points less likely to use an informal attendant. In contrast, women in rural areas are about 2 percentage points more

\footnotetext{
${ }^{28}$ We calculated the geodesic distance between each cluster and the closest health facility that provides delivery services by linking the DHS GPS data to our geocoded health facility data. 22 DHS clusters (out of 849) did not have GPS coordinates and were dropped from the analysis. The wealth index was constructed by aggregating information on dwelling characteristics and household assets using principal component analysis.
} 
likely to use an informal attendant. Next we examine what happened to these births.

\subsection{What was the effect of the ban on the use of formal sector care and other informal alternatives?}

We first examine the effect of the ban on the use of formal-sector providers. Figure 5 plots trends in the use of formal sector care for high- and low- exposure villages. We see a large increase in the probability that a baby was delivered by a formal sector health provider in high-exposure villages within a year of the ban being implemented. In contrast, in low-exposure villages there was no noticeable change over the same period. The regression results in Table 6 confirm this. The probability that a birth was attended by a formal sector provider increased by about 11 percentage points in our most conservative specification (approximately three-quarters of the decline in births attended by informal birth attendants). In Table 7 we show that there was a small increase in relative/friend-attended births (about 4 percentage points). Consistent with higher substitution costs, we find that this increase in the use of other informal substitutes was primarily among mothers for whom distance was a perceived barrier to use of health services. ${ }^{29}$ We however find no statistically significant evidence of an increase in unattended deliveries (Columns 3 and 4). From Tables 5-7, we conclude that births largely shifted from the informal to the formal sector.

\subsection{What was the effect of the ban on newborn mortality?}

Overall, the ban appears to have successfully shifted a large fraction of births from informal to formal sector providers. Given this we examine whether this led to a reduction in newborn deaths. We take advantage of the fact that the DHS collects mortality information for all births, not just those within the last five years, allowing us to study mortality trends over a longer period of time. To mitigate concerns about accuracy of maternal recall, we restrict our attention to births within the last ten years. ${ }^{30}$ Studies show that mothers are able to accurately recall significant pregnancy-

\footnotetext{
${ }^{29}$ In the MDHS, women are asked whether distance is a 'big problem' for seeking care. $58 \%$ of women answered "Yes" to this question. We estimate fully interacted models using this binary variable (see Table 11). The coefficient for women for whom distance is a big problem is nearly double the size for women for whom distance is not a big problem (0.043 vs. 0.027$)$, though the difference does not quite attain statistical significance.

${ }^{30} \mathrm{We}$ assess the robustness of the results to changing the recall period. In Appendix Table 1 Panel A, we present mortality regressions with a recall period of five years to be consistent with the time period over which we observe birth location (and also to help reduce potential recall bias), and in Panel B, we extend the recall window from 10 to 20 years (there are more observations but at the risk of potentially increasing recall bias. In both cases the results are qualitatively similar to our main results.
} 
related events up to 10 years after the birth (Yawn et al., 1998; Sou et al., 2006). Following standard practice in demography, we focus our attention on singleton births. Our primary outcome is a binary indicator for a newborn death. We distinguish between a death within the first month of life (a neonatal death) and a death within the first week (an early neonatal death). The latter is thought to be a good indicator of the quality of delivery care (Ngoc et al., 2006). To ensure that all births are fully exposed to the neonatal period, we drop 507 births that occurred in the month of, and the month immediately preceding, the month of interview. Our final sample consists of 35,246 singleton births born to mothers since January 2001.

In Figure 6 we plot trends in newborn mortality for high- and low-exposure villages. Until 2005, both trend lines appear to be largely parallel. There is a puzzling drop in 2005 in low-exposure areas and a rebound the following year. ${ }^{31}$ Though we cannot reject the null of similar trends as shown in Table 2, we allow for flexible time trends that vary by district. We also estimate a triple difference specification using young (unexposed) children in the same areas as a control group. This is described in the next section. The regression results are in Tables 8 and 9. Table 8 shows the effect of the ban on early neonatal deaths (deaths within the first week) while Table 9 shows results for neonatal deaths (deaths within the first month). Like before, Column 1 shows the basic specification with district and year x month fixed effects, Column 2 includes controls, in Column 3 we interact all the control variables with the Post indicator, Column 4 includes district-specific time trends, and in column 5 we drop villages with baseline informal birth attendance use equal to 0 or 1 . Column 6 is equivalent to Column 3 except that district fixed effects have been replaced with cluster fixed effects.

Across all the specifications we find no statistically significant evidence of a reduction in newborn mortality (coefficients have been multiplied by 1,000 to allow interpretation as $X$ per 1,000 live births). In our preferred specification in Column 5, which corresponds to the most conservative specification from Tables 5 and 6, the coefficient even has the wrong sign. Even if we ignore this positive coefficient and consider the magnitudes of the negative coefficients, the effects implied by the point estimates are quite small. One can, for example, compare them to the effect of maternal age and paternal schooling in the model, both of which are potentially malleable factors. The

\footnotetext{
${ }^{31}$ One possibility is that this was due to the food crisis of $2005 / 06$. Early heavy rains and limited rains later on in the season resulted in poor crop yields in 2005, and the resulting food crisis of 2005/06. This may have had a greater impact in low-exposure areas.
} 
coefficients on the included controls are consistent with the broader literature. We find that both first births, male births, and young mothers all have a significantly higher mortality risk, paternal schooling on the other hand is associated with a lower risk of a newborn death. In the next section we discuss several robustness checks.

\subsection{Robustness checks}

\subsubsection{Are the results sensitive to choice of threshold?}

As noted earlier, our choice of the $75^{t h}$ percentile for high exposure may be considered to be somewhat arbitrary and so we assess whether the results are sensitive to the choice of the cutoff. In Figure 7 we graph, for each of the main outcomes, the point estimates and confidence intervals obtained from regressions where we iteratively vary the cutoff from the $50^{\text {th }}$ to the $85^{\text {th }}$ percentiles. The regression specification used is our preferred specification in Column 5. We see that the results are robust to the choice of cutoff. Panels $\mathrm{A}$ and $\mathrm{B}$ show that as the definition of high-exposure becomes more restrictive, the effects become larger. Panels $\mathrm{C}$ and $\mathrm{D}$ document consistent zero effects across a wide range of thresholds. ${ }^{32}$

\subsubsection{Inclusion of stillbirths}

Next we assess the robustness of the results to the inclusion of stillbirths. It is possible that for babies that die shortly after birth, formal and informal birth attendants may explain this outcome differently to mothers. If informal birth attendants are more likely to say that the child was born dead (to avoid being blamed for the death) whereas a provider in the formal sector is more likely to report that the child was born alive but died (or vice-versa), this introduces systematic measurement error because the former would be classified as a stillbirth whereas the latter would be reported as an early neonatal death. ${ }^{33}$ To address this we examine whether the results are sensitive to the

\footnotetext{
${ }^{32}$ As an additional check, Appendix Table 2 presents the results using the actual rate of informal birth attendant use at baseline rather than the binary indicator for high exposure. We see that the qualitative results are not sensitive to defining exposure as a continuous instead of a binary variable.

${ }^{33}$ We thank the editor for raising this point as well as a related point about whether the ban might have affected the probability of a fetal loss during the pregnancy. The logic being that if the ban induced more women to use a formal sector provider during the pregnancy, this might result in less fetal loss. Such babies might then be more likely to die during the first week or first month. In other words, there are offsetting effects - babies are healthier under formal sector care, but more babies with health problems are also born under such care. In Appendix Table 4, we show that the ban did not increase the number of prenatal visits, nor did it change the likelihood of using a formal sector provider during the pregnancy. As a caveat we note that most prenatal care in Malawi was already
} 
inclusion of stillbirths (when stillbirths are included with early neonatal deaths, this is known as perinatal mortality). The MDHS includes the following question: "Have you ever had a pregnancy that miscarried, was aborted, or ended in a stillbirth?" We code all pregnancies that ended in or after the seventh month as a stillbirth. The results are presented in Appendix Table 3. Our qualitative conclusions are unchanged.

\subsubsection{Triple difference approach}

As we noted previously, our estimation strategy assumes that nothing changed differentially over time in high- and low-exposure areas. Although we allow for district-specific time trends, this may not fully account for differential changes within districts. As a robustness check, we estimate triple difference models where we compare changes in mortality among newborn infants (the 'treated' group) to changes in mortality among young children - 2-5 year olds - (the 'control' group) in highvs. low-exposure areas. In this triple difference specification, young children serve as a withinarea control group allowing us to purge our estimates of the confounding effects of any differential unobserved shocks to child mortality. In this case, we are assuming that time varying shocks that affect high and low exposure areas differentially would not differentially impact infants and young children. The results from the triple difference specification are reported in Table 10. We obtain largely similar results.

\subsection{Why did increased use of formal care not translate into lower mortality?}

The results we have just shown suggest that though the ban successfully shifted births from the informal to the formal sector this did not translate into a measurable reduction in newborn deaths. In the specification corresponding to the most conservative effects of the ban on informal/formal provider use, the coefficient on early newborn mortality is positive though not statistically significant. The $95 \%$ confidence interval allow us to rule out an effect size greater than roughly 6 deaths per 1,000 live births. Even if we ignored the positive (wrong-signed) coefficient and focused on the negative coefficient in Column 4 of Table 8, the point estimate implies a small effect - a reduction in early newborn mortality of less than 1 death per 1,000 live births (the estimated effect on 30-day

provided by the formal sector - prior to the ban less than $2 \%$ of women received prenatal care from an informal birth attendant. Since the ban did not change patterns of prenatal care, this mechanism seems highly unlikely. 
mortality is only slightly larger). This is an intent-to-treat estimate since the ban did not achieve $100 \%$ compliance, but a quick calculation simulating full compliance and scaling up the negative coefficient would still imply only a small reduction in early newborn mortality - about 2 deaths per 1,000 live births (less than $10 \%$ relative to the baseline). ${ }^{34}$ This raises the question of why the ban did not reduce newborn mortality on average. Below we consider several alternative explanations.

\subsubsection{Was there an offsetting effect of relative/friend-attended births?}

Previously we showed that there was not a 1:1 substitution between informal and formal birth attendants, some women appear to have substituted towards relative/friend-attended births. If these women experienced worse outcomes on average, this might offset any potentially beneficial effects of increased use of formal sector care. Given that the increase in use of formal providers was nearly three times the increase in use of relative-friend-attended births (11 compared to 4 percentage points), it seems unlikely that any adverse effects of relative/friend attended births would completely swamp the beneficial effects of formal sector care, nevertheless, to try to rule this out, we take advantage of the fact that the substitution towards relative/friend-attended births was largely among women with high travel costs (women who reported that distance was a 'big problem' in accessing services). We run separate regressions for women with high and low travel costs (see Table 11) and find that if anything the results run in the opposite direction - the coefficient on mortality is negative for women with high travel costs, who were more likely to substitute towards relatives/friends, and positive for the other women. From this result, we conclude that there is no evidence of any offsetting effects.

\subsubsection{Are 'compliers' women with low returns to formal care?}

Another alternative that we consider is that the women who were induced by the ban to switch to formal sector care are women with low returns to formal care. The marginal health gain of switching from an informal to a formal sector provider is likely to depend on pregnancy risk. Lowrisk pregnancies would likely have a good outcome regardless of whether they were attended by a formal or informal provider, implying that the marginal returns to formal care are low. It is

\footnotetext{
${ }^{34}$ The ban conservatively reduced use of informal birth attendants by 15 percentage points. Since the baseline is $45 \%$, to simulate $100 \%$ compliance we scale up the mortality estimate by a factor of three i.e., $-0.00065^{*} 3$.
} 
therefore important to explore whether the compliers in this natural experiment are low-risk women. Following the medical and epidemiological literature (McMillen, 1979; Vogel et al., 2013), we classify the following as higher risk: (i) male births, (ii) multiple births, (iii) first births, and (iv) young mothers (age $<18$ years). Our data show that, consistent with the literature, these variables are associated with a greater probability of a newborn death. Following Angrist and Pischke (2009), we estimate the relative likelihood that compliers possess some Bernoulli-distributed characteristic, $X$ using the following expression:

$$
\frac{P\left[x_{1 i}=1 \mid D_{1 i}>D_{0 i}\right]}{P\left[x_{1 i}=1\right]}=\frac{E\left[D_{i} \mid Z_{i}=1, x_{1 i}=1\right]-E\left[D_{i} \mid Z_{i}=0, x_{1 i}=1\right]}{E\left[D_{i} \mid Z_{i}=1\right]-E\left[D_{i} \mid Z_{i}=0\right]}
$$

$D_{i}$ denotes treatment (in this case, using a formal sector provider), $Z_{i}$ is the instrument (in this case, the interaction between exposure and Post), and 0 and 1 denote potential outcomes. We also estimate the mean of each characteristic for compliers using the kappa-weighting scheme suggested by Abadie (2003) and compare with the average. The results are in Table 12. We see that, overall, compliers appear more likely to be higher risk - they are $31 \%$ more likely to be first-time mothers, and $32 \%$ more likely to be carrying a multiple pregnancy. From this we conclude that the compliers are not unusually low risk.

\subsubsection{Is the quality of formal care a constraint?}

The final explanation that we consider is that low average quality constrains improvements in health outcomes. There is a fair amount of literature that shows that the quality of formal sector care is quite low on average (Chaudhury et al., 2006; Banerjee et al., 2004; Das et al., 2008, 2012). Harvey et al. (2007) for example finds that only half of assessed providers in five countries were competent to perform newborn resuscitation. Ronsmans et al. (2009) show that midwives are not skilled at managing delivery complications even when women present early. It is also well known that many health facilities, particularly those at the primary level, lack necessary equipment and supplies to deliver high-quality care. To explore the potential importance of quality of care in the formal sector, we turn to our health facility dataset.

The dataset contains information that allows us to construct an index of the facility's ability to deliver high-quality care, such as whether the facility has an on-site laboratory, whether trained 
clinical staff are available 24 hours a day, and whether the facility can carry out blood transfusions. The indicators we use in constructing the quality index are shown in Table 13. A limitation of these indicators is that they primarily measure structural quality and may not adequately capture other relevant dimensions of quality such as the process of care. However, the process of care is notoriously hard to measure - clinical vignettes tend to measure competence but may not be a good representation of what the provider would do in practice (Das and Hammer, 2004); direct observation induces Hawthorne effects (Leonard and Masatu, 2010), and the use of standardized patients is very expensive and can usually only be used on a small scale (Das et al., 2012).

We assign each facility a quality score based on these indicators - we score one point for each indicator and sum the scores. The minimum score is 0 , the maximum is 8 . The distribution is shown in Figure 8. We classify facilities with a score within the top quartile of the distribution as high-quality facilities. In Table 14 we present separate results for households with access to highquality formal care (defined based on whether the nearest health facility is a high-quality facility) and households without. We find that, consistent with quality being an important constraint, there is a statistically significant reduction in newborn mortality for households with access to high quality formal care but not for other households. The coefficients indicate about a 1.3-1.4 percentage point decrease in newborn mortality within the first week and a 1.6-1.8 percentage point decrease in newborn mortality within the first month. The coefficients for households with access to lower-quality care are generally positive, though not statistically significant. As a robustness check, we estimate the earlier triple difference specification for each group of households (i.e. by quality quartiles). We note that this corresponds to a quadruple difference - the first difference is between high- and low-exposure areas, the second difference is before and after the ban, the third difference is between newborns and young children, and the fourth difference is between households with good access to high-quality formal sector care and those with poor access. The results continue to hold (see Appendix Table 5).

\section{Conclusion}

Informal health providers are ubiquitous in developing countries, and play a particularly important role in the provision of maternal care. These informal (or traditional) birth attendants, as 
they are known, attend up to half of all deliveries, and provide a range of other maternal and child health services. Their use is however controversial because they are not formally trained and many people believe that the poor quality of care they provide leads to preventable deaths. Recently, some countries have instituted bans (enforced by fines and penalties) to prevent the use of these informal attendants. The goal of these bans is to shift births from informal to formal settings. Since the quality of care is believed to be higher in the formal sector, this policy is expected to reduce mortality. However it is not a priori clear that either of these assumptions is necessarily true. It has been argued that informal attendants play a critical role, particularly in rural areas, and that a ban might induce women to give birth unassisted, or might force this practice underground. There is also plenty of research that raises questions about whether formal sector providers deliver better care in practice. This paper provides the first empirical examination of the effects of a ban on informal health workers.

In 2007, the Malawi government imposed a ban on the use of informal birth attendants in an effort to reduce mortality rates that were some of the highest in the world. Newspaper reports and anecdotal evidence from Malawi suggests that the ban was enforced. To estimate the causal effect of the ban, we employ a difference-in-difference strategy that exploits variation across time and space in the intensity of exposure to the ban. We show that the ban significantly reduced the use of informal providers - by about 15 percentage points based on our most conservative estimate (relative to a baseline mean of about 45 percent). Consistent with policy objectives, the ban shifted births to the formal sector. We show that the ban conservatively increased use of formal sector providers by about 11 percentage points, with a small increase in the use of other informal alternatives, primarily, relatives and friends. Importantly however, we find no evidence that the ban led to an increase in unattended births. Despite the large shift in births from informal to formal settings, we found limited evidence of a reduction in newborn mortality on average.

To understand why the shift from informal to formal providers did not translate into mortality reductions, we explore three alternative explanations. First, we examine whether there were offsetting effects from the (small) increase in use of relative/friend-attended births - increased mortality from relative/friend-attended births might offset reduced mortality from increased use of formal care. Second, we examine whether the mothers induced by the ban to use formal services (the compliers) were low risk. Third, we examine whether low average quality acts as a constraint on 
health improvements. We do not find evidence for the first two explanations: our results instead are consistent with the 'low quality' hypothesis. We find that mothers with access to high-quality formal sector care - defined based on the closest health facility - had a lower probability of a newborn death after the ban is introduced. Since most women did not have 'access' to a high quality facility - and our results suggest that there was no (measurable) benefit to using these facilities this helps to explain why, on average, there was no effect of the increased use of formal sector care on newborn mortality. This type of policy may therefore help to exacerbate inequalities in health outcomes unless there are simultaneous efforts to improve the quality of formal sector care.

The findings in this study add to a growing body of evidence that show that increasing the use of formal health providers and facilities, by itself, does not lead to significant improvements in health outcomes. Okeke and Chari (2014), for example, exploit the randomized scale-up of a performancebased financing program in Rwanda and find that despite a large increase in institutional deliveries as a result of the program, there was no reduction in newborn mortality. Mazumdar et al. (2011) evaluate the effect of a large conditional cash transfer program in India, the Janani Suraksha Yojana (JSY), that incentivizes women to give birth in formal facilities but find no effect of the JSY on newborn mortality. See also Mohanan et al. (2014), who find no effect of a separate program in India that covered the costs of deliveries at private-sector hospitals for households below the poverty line. The results in this paper help to resolve this seeming puzzle. We show that increased use of formal care does improve outcomes but only for those with access to high quality care. These findings suggest that supply-side improvements should be a priority for policy maker efforts if the objective is to reduce mortality.

What are the welfare implications of a ban on informal attendants and is this a good policy? Our results paint a mixed picture. While we find evidence of decreased newborn mortality for some households, most households experienced no such gains and likely incurred significant costs to use formal sector care (higher travel costs and higher fees in the formal sector). As a caveat, we note that we are only able to look at child outcomes and are not able to estimate the effects of the ban on maternal health outcomes because of limitations of the available data. ${ }^{35}$ The economic rationale for

\footnotetext{
${ }^{35}$ The DHS asks all women about their female siblings and whether they are alive/dead and how they died. This allows one to construct a measure of maternal mortality. However, siblings do not necessarily reside in the same village and this is particularly true post-marriage. This introduces considerable measurement error in an outcome that is an already rare event. In ongoing work elsewhere we are able to look at maternal health outcomes.
} 
government intervention in markets is usually to correct a market failure and it is not clear whether this rationale extends to the informal health sector. Government intervention may be warranted, for example, if informal sector providers deliver care that is harmful and information frictions prevent households from perceiving this, or if households systematically underestimate the returns to formal care. $^{36}$

On the one hand, our results suggest that women may (correctly) perceive that, on average, there is little gain to switching to the formal sector, and may therefore be making rational choices to use informal attendants; on the other hand however, we find that there are some women who would benefit from using formal care who are not (and who would not be in the absence of the ban). In other words, some women are making the 'wrong' decision. This suggests that there is room for welfare-improving policy. A ban, however, given the distribution of costs and benefits, may be too heavy-handed an instrument and other ways to get the right women to use services may be more appropriate.

\footnotetext{
${ }^{36}$ Another potential rationale is if there are negative externalities such as in the case of antibiotic resistance from improper prescribing.
} 


\section{References}

Abadie, A. (2003). Semiparametric instrumental variable estimation of treatment response models. Journal of Econometrics, 113(2):231 - 263.

Adda, J. and Cornaglia, F. (2010). The effect of bans and taxes on passive smoking. American Economic Journal: Applied Economics, 2(1):1-32.

Adhvaryu, A. and Nyshadham, A. (2014). Returns to treatment in the formal health care sector: Evidence from Tanzania. American Economic Journal: Economic Policy, Forthcoming.

Almond, D. and Doyle, J. J. (2011). After midnight: A regression discontinuity design in length of postpartum hospital stays. American Economic Journal: Economic Policy, 3(3):1-34.

Almond, D., Doyle, J. J., Kowalski, A. E., and Williams, H. (2010). Estimating marginal returns to medical care: Evidence from at-risk newborns. Quarterly Journal of Economics, 125(2):591-634.

Angrist, J. D. and Pischke, J.-S. (2009). Mostly harmless econometrics: An empiricist's companion. Princeton University Press.

Banerjee, A., Deaton, A., and Duflo, E. (2004). Health Care Delivery in Rural Rajasthan. Economic and Political Weekly, 39(9):944-49.

Beckett, M., Vanzo, J. D., Sastry, N., Panis, C., and Peterson, C. (2001). The quality of retrospective data: An examination of long-term recall in a developing country. Journal of Human Resources, 36(3):593-625.

Bergström, S. and Goodburn, E. (2001). The role of traditional birth attendants in the reduction of maternal mortality. Studies in Health Service organization and Policy, 17:85-89.

Bhutta, Z. A., Das, J. K., Bahl, R., Lawn, J. E., Salam, R. A., Paul, V. K., Sankar, M. J., Blencowe, H., Rizvi, A., Chou, V. B., and Walker, N. (2014). Can available interventions end preventable deaths in mothers, newborn babies, and stillbirths, and at what cost? The Lancet, 384(9940):347 -370 .

Bisika, T. (2008). The effectiveness of the TBA Programme in reducing maternal mortality and morbidity In Malawi. East African Journal of Public Health, 5(2):103-110.

Buchmueller, T. C., Jacobson, M., and Wold, C. (2006). How far to the hospital? the effect of hospital closures on access to care. Journal of Health Economics, 25(4):740 - 761.

Chaudhury, N., Hammer, J. S., Kremer, M., Muralidharan, K., and Rogers, H. F. (2006). Missing in action: Teacher and health worker absence in developing countries. Journal of Economic Perspectives, 20(1):91-116. 
Chen, C., Wang, J. D., Ward, A. L., Chan, C. C., Chen, P. C., Chiang, H. C., Kolola-Dzimadzi, R., Nyasulu, Y. M. Z., and Kwong-Leung Yu, J. (2011). The effectiveness of continuing training for traditional birth attendants on their reproductive health-care knowledge and performance. Midwifery, 27:648-653.

Cheng, C. (2012). The effect of cell phone bans on driver behavior: Accidents and casualties. College Station, TX: Department of Economics, Texas A\&M University.

Darmstadt, G. L., Lee, A. C., Cousens, S., Sibley, L., Bhutta, Z. A., Donnay, F., Osrin, D., Bang, A., Kumar, V., Wall, S. N., Baqui, A., and Lawn, J. E. (2009). 60 million non-facility births: Who can deliver in community settings to reduce intrapartum-related deaths? International Journal of Gynecology \& Obstetrics, 107, Supplement(0):S89-S112.

Das, J., Hammer, J., and Leonard, K. (2008). The quality of medical advice in low-income countries. Journal of Economic Perspectives, 22(2):93-114.

Das, J. and Hammer, J. S. (2004). Which Doctor? Combining Vignettes and Item Response to Measure Doctor Quality. World Bank Policy Research Working Paper No. 3301.

Das, J., Holla, A., Das, V., Mohanan, M., Tabak, D., and Chan, B. (2012). In urban and rural india, a standardized patient study showed low levels of provider training and huge quality gaps. Health Affairs, 31(12):2774-2784.

Harvey, S. A., Blandón, Y. C., McCaw-Binns, A., Sandino, I., Urbina, L., Rodríguez, C., Gómez, I., Ayabaca, P., Djibrina, S., and the Nicaraguan maternal and neonatal health quality improvement group (2007). Are skilled birth attendants really skilled? a measurement method, some disturbing results and a potential way forward. Bulletin of the World Health Organization, 85(10):783-790.

Hussein, A. K. and Mpembeni, R. (2005). Recognition of High Risk Pregnancies and Referral Practices among Traditional Birth Attendants in Mkuranga District, Coast Region, Tanzania. African Journal of Reproductive Health, 9(1):113-122.

Kumar, A. (2007). The Examination of Traditional Birth Attendant Practices and Their Role in Maternal Health Services in Mwandama Village Cluster. Master's thesis, University of Malawi College of Medicine.

Lawn, J. E., Lee, A. C., Kinney, M., Sibley, L., Carlo, W. A., Paul, V. K., Pattinson, R., and Darmstadt, G. L. (2009). Two million intrapartum-related stillbirths and neonatal deaths: Where, why, and what can be done? International Journal of Gynecology 85 Obstetrics, 107, Supplement(0):S5S19.

Leonard, K. L. and Masatu, M. C. (2010). Using the hawthorne effect to examine the gap between a doctors best possible practice and actual practice. Journal of Development Economics, 93(2):226243. 
Levin, A., Dmytraczenko, T., McEuen, M., Ssengooba, F., Mangani, R., and Van Dyck, G. (2003). Costs of maternal health care services in three anglophone african countries. The International journal of health planning and management, 18(1):3-22.

Mazumdar, S., Mills, A., and Powell-Jackson, T. (2011). Financial Incentives in Health: New Evidence from India's Janani Suraksha Yojana. SSRN Working Paper. Available at SSRN: http://ssrn.com/abstract=1935442.

McMillen, M. (1979). Differential mortality by sex in fetal and neonatal deaths. Science, 204(4388):89-91.

Ministry of Health (2007). Assessment of future roles of traditional birth attendants in maternal and neonatal health in Malawi. Technical report, Ministry of Health, Republic of Malawi.

Mohanan, M., Bauhoff, S., La Forgia, G., Babiarz, K. S., Singh, K., and Miller, G. (2014). Effect of Chiranjeevi Yojana on institutional deliveries and neonatal and maternal outcomes in Gujarat, India: a difference-in-differences analysis. Bulletin of the World Health Organization, 92(1):187194.

Montagu, D., Yamey, G., Visconti, A., Harding, A., and Yoong, J. (2011). Where do poor women in developing countries give birth? a multi-country analysis of demographic and health survey data. PLoS ONE, 6(2):e17155.

Nandi, A. and Deolalikar, A. B. (2013). Does a legal ban on sex-selective abortions improve child sex ratios? Evidence from a policy change in India. Journal of Development Economics, 103(0):216 $-228$.

National Statistical Office, Malawi and United Nations Children's Fund (UNICEF) (2008). Malawi Multiple Indicator Cluster Survey, 2006. Final report. Technical report, NSO and UNICEF, Lilongwe, Malawi.

Ngoc, N., Merialdi, M., Abdel-Aleem, H., Carroli, G., Purwar, M., Zavaleta, N., Campódonico, L., Ali, M. M., Hofmeyr, J. G., Mathai, M., Lincetto, O., and Villar, J. (2006). Causes of stillbirths and early neonatal deaths: data from 7993 pregnancies in six developing countries. Bulletin of the World Health Organization, 84(9):699-705.

Ofili, A. N. and Okojie, O. H. (2005). Assessment of the role of traditional birth attendants in maternal health care in Oredo Local Government Area, Edo State, Nigeria. Journal of Community Medicine and Primary Health Care, 17(1):55-60.

Okeke, E. N. and Chari, A. (2014). Can Institutional Deliveries Reduce Newborn Mortality? Evidence from Rwanda. RAND Working Paper 1072.

Osili, U. O. and Long, B. T. (2008). Does female schooling reduce fertility? evidence from Nigeria. Journal of Development Economics, 87(1):57-75. 
Rajaratnam, J. K., Marcus, J. R., Flaxman, A. D., Wang, H., Levin-Rector, A., Dwyer, L., Costa, M., Lopez, A. D., and Murray, C. J. (2010). Neonatal, postneonatal, childhood, and under-5 mortality for 187 countries, 1970-2010: a systematic analysis of progress towards millennium development goal 4. The Lancet, 375(9730):1988-2008.

Ronsmans, C., Scott, S., Qomariyah, S., Achadi, E., Braunholtz, D., Marshall, T., Pambudi, E., Witten, K., and Graham, W. (2009). Professional assistance during birth and maternal mortality in two indonesian districts. Bulletin of the World Health Organization, 87:416-423.

Sou, S., Chen, W., Hsieh, W., and Jeng, S. (2006). Severe obstetric complications and birth characteristics in preterm or term delivery were accurately recalled by mothers. Journal of Clinical Epidemiology, 59(4):429-443.

Starrs, A. (2006). Safe motherhood initiative: 20 years and counting. The Lancet, 368:1130-1132.

Sudhinaraset, M., Ingram, M., Lofthouse, H. K., and Montagu, D. (2013). What is the role of informal healthcare providers in developing countries? a systematic review. PLoS ONE, 8(2):e54978.

Titaley, C., Hunter, C., Dibley, M., and P., H. (2010). Why do some women still prefer traditional birth attendants and home delivery? A qualitative study on delivery care services in West Java Province, Indonesia. BMC Pregnancy and Childbirth, 10(43):1-14.

Valente, C. (2014). Access to abortion, investments in neonatal health, and sex-selection: Evidence from Nepal. Journal of Development Economics, 107(0):225 - 243.

Vogel, J. P., Torloni, M. R., Seuc, A., Betrán, A. P., Widmer, M., Souza, J. P., and Merialdi, M. (2013). Maternal and perinatal outcomes of twin pregnancy in 23 low- and middle-income countries. PLoS ONE, 8(8):e70549.

World Bank (2014). World Development Indicators, World Bank, Washington.

World Health Organization (1992). Traditional birth attendants: a joint WHO/UNICEF/UNFPA statement. Technical report, Geneva, Switzerland: World Health Organization.

Yawn, B., Suman, V., and Jacobsen, S. (1998). Maternal recall of distant pregnancy events. Journal of Clinical Epidemiology, 51(5):399-405.

Young, M. (2010). Malawi president reverses national law after health reports highlight troubles for pregnant women. Available at: http://tinyurl.com/kpghzmk. Last accessed July 23, 2014. 


\section{Appendix A}

We carry out additional validity checks using a different dataset - the Malawi Integrated Household Survey (IHS). The IHS is a nationally representative household survey that collects extensive data on agricultural production, income and consumption. We use these data to: (a) examine whether there were differential changes pre- and post-intervention using additional variables (similar to Table 4); (b) explore whether households in high-exposure areas were exposed to more/fewer shocks over time that might affect child mortality. For our analysis we use the 2004 and 2010 waves of the IHS. We note some important limitations: first we cannot readily match the IHS to the MDHS (earlier waves of the IHS did not collect GPS coordinates and even when GPS coordinates are available the clusters sampled largely do not overlap with the MDHS), we also cannot readily match clusters within the IHS across waves (largely different clusters were sampled in both waves). Therefore, we have to rely on a less sharp definition of exposure to treatment that is not directly comparable to the measures used in the main analysis. Second, comparability across waves is a problem because questions change over time, this restricts the range of variables that we can consider. With these caveats in mind we present the results.

In Table A.6, we test whether there are differential changes in household characteristics between 2004 and 2010. As we have noted because clusters cannot be matched consistently between the MDHS and the IHS, we construct the exposure indicator at a more aggregate level that we can match across datasets. Specifically, we construct baseline prevalence of informal birth attendant use for each district by rural/urban status using the MDHS. Then using the same approach taken in the paper, we define exposure equal to one if the cell exceeds the 75 th percentile in the sample; and zero otherwise. We then apply exposure status to the IHS. Post is equal to one if the data comes from the 2010 wave. Similar to our finding using the MDHS, we do not find differential changes in household characteristics between 2004 and 2010.

In Table A.7 we look specifically at a range of household shocks that may be correlated with child mortality. The IHS collects information about a range of households shocks and respondents are asked whether or not they experienced a particular shock. As we have noted previously, there are some issues with comparability across waves. For example in 2004, the IHS asked about shocks in the last five years, while in 2010, respondents were asked about shocks in the last year. In 
order to ensure comparability of indicators across waves we have aggregated some shocks that were listed separately in one round of the survey and jointly in a different round. For example, in 2004 respondents were asked about droughts and floods jointly, whereas in 2010 respondents were asked about each one separately. With this limitation in mind, we show that the results are broadly supportive of our identification strategy.. 


\section{Figure 1}

\section{Formal sector care and newborn mortality}

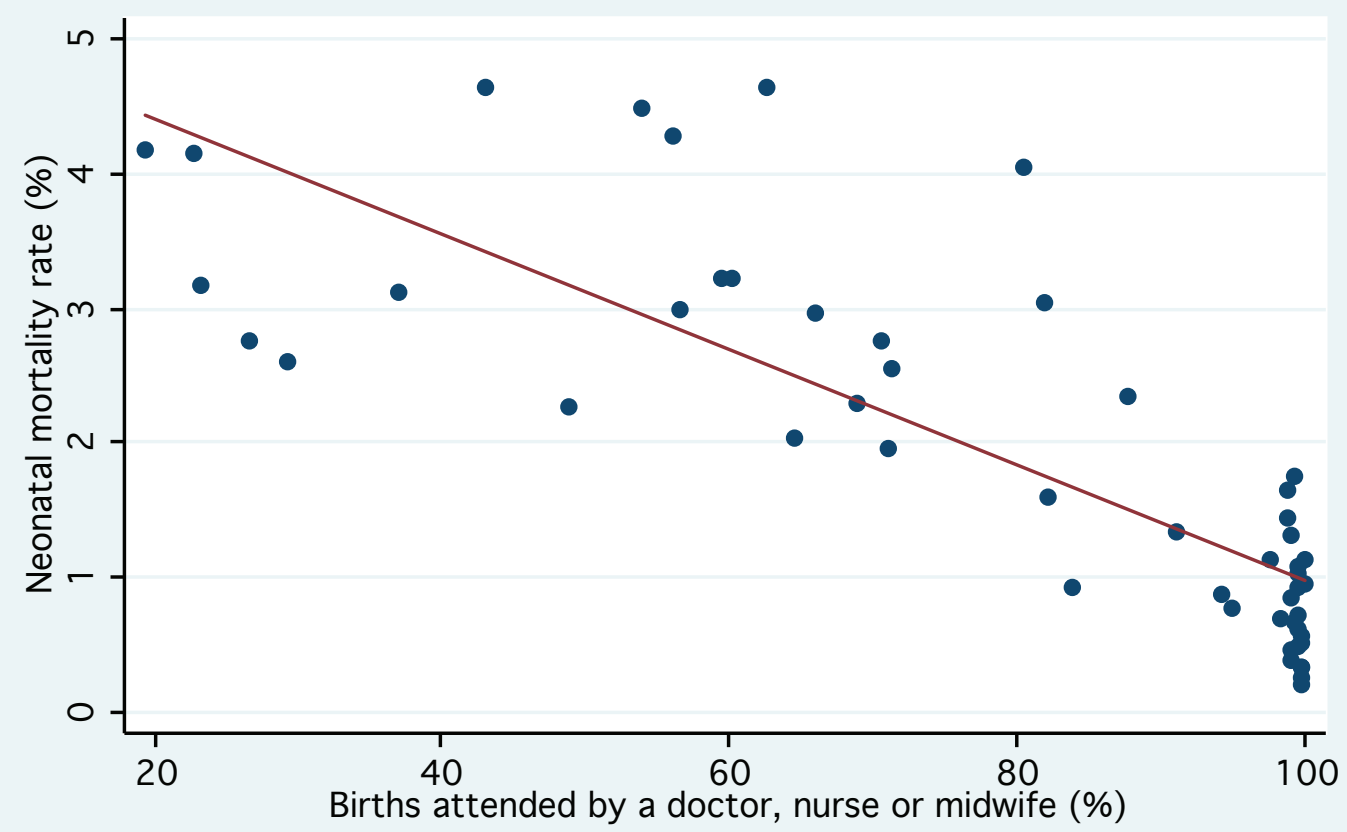

Notes: This figure shows the cross-sectional correlation between the percentage of births attended by a doctor, nurse, or midwife and the neonatal mortality rate for 52 countries in 2010. Source of data is the World Bank Health Nutrition and Population Statistics database. 
Figure 2

Change in the use of informal birth attendants by baseline distribution

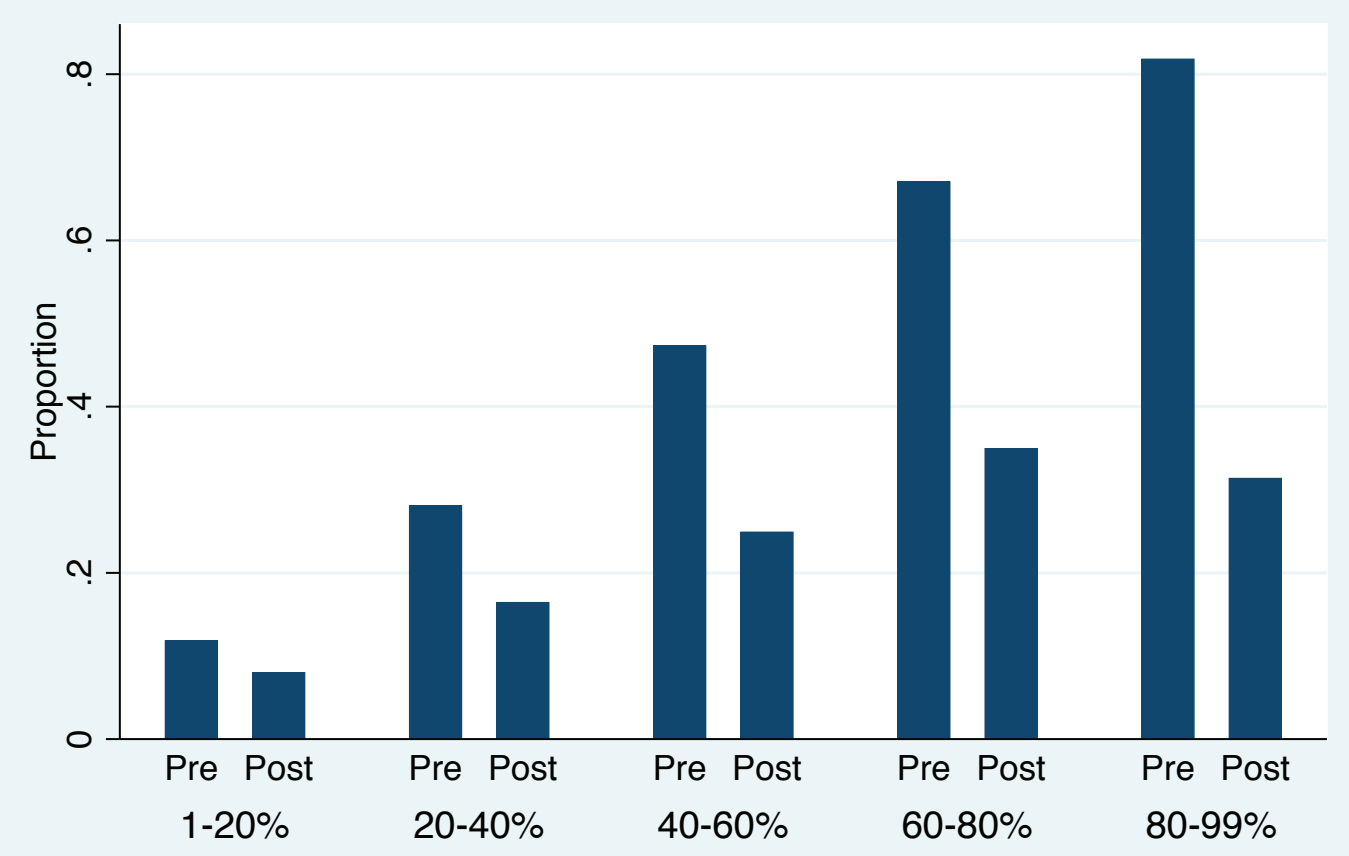

Notes: X-axis shows the historical rate of informal birth attendant use grouped into five categories. We exclude villages with values of 0 and 1 . 
Figure 3

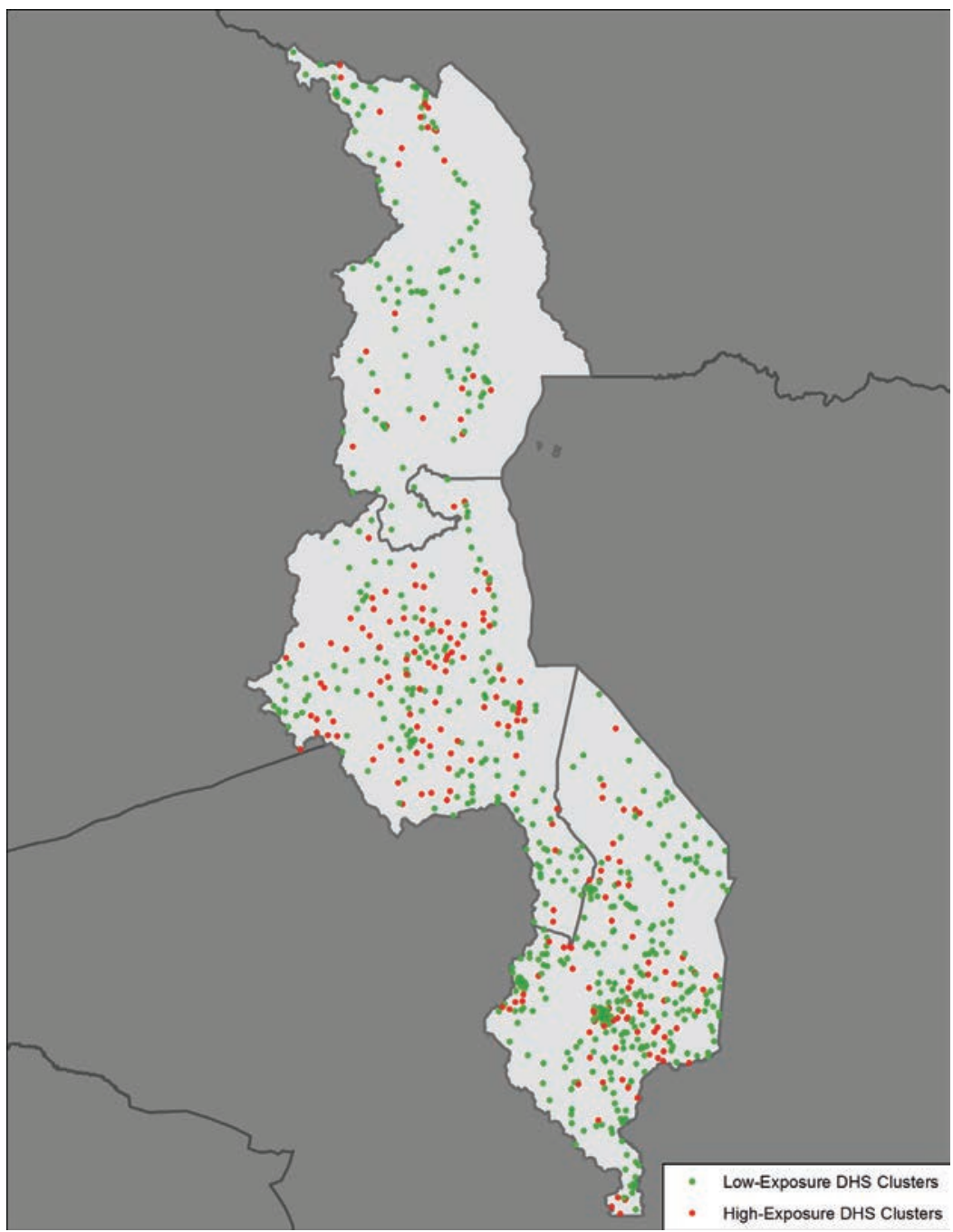

Notes: The figure above is a GIS map of Malawi showing high and low-exposure clusters. 


\section{Figure 4}

\section{Use of informal birth attendants}

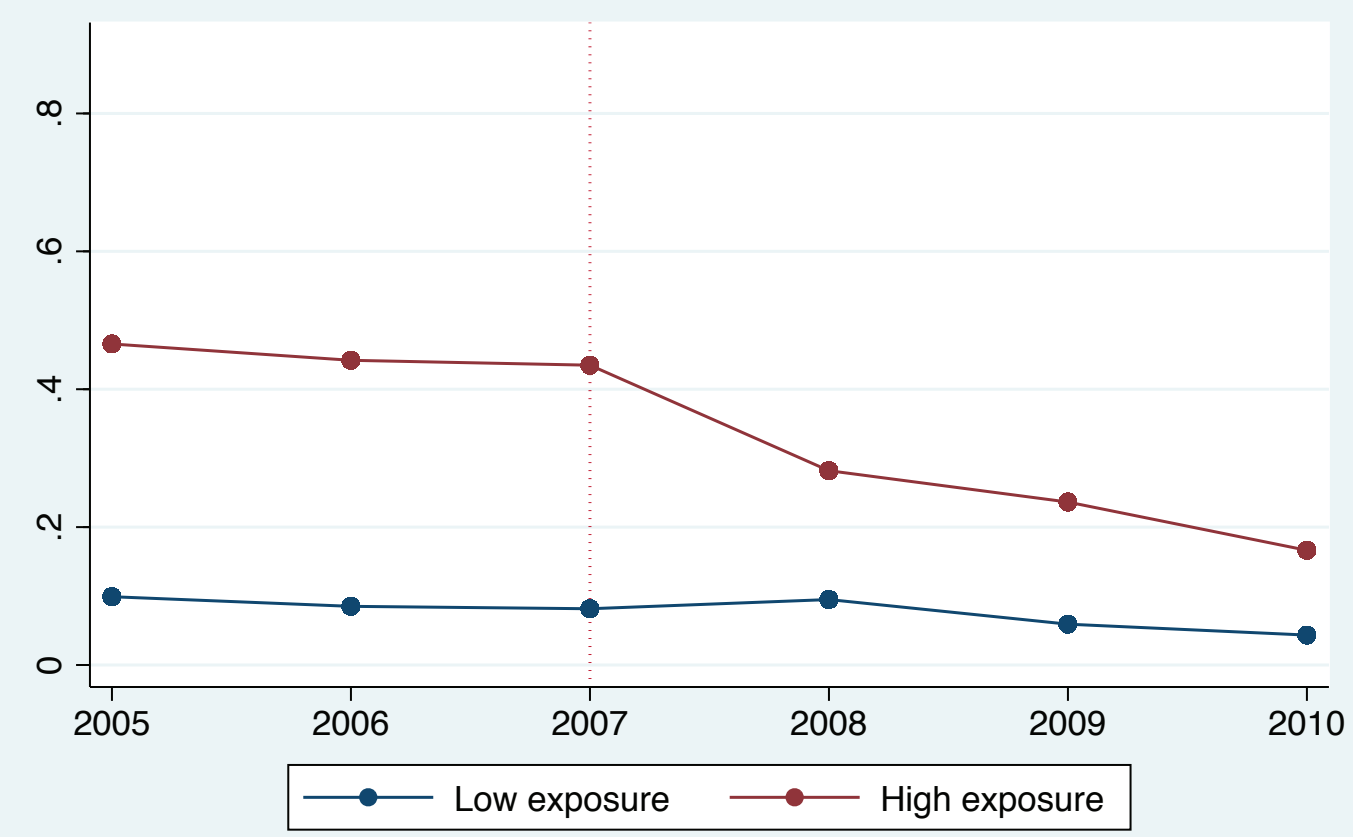

Notes: This figure plots trends in use of informal birth attendants in high- and lowexposure villages. Dotted line indicates when the ban went into effect. 
Figure 5

\section{Use of formal sector providers}

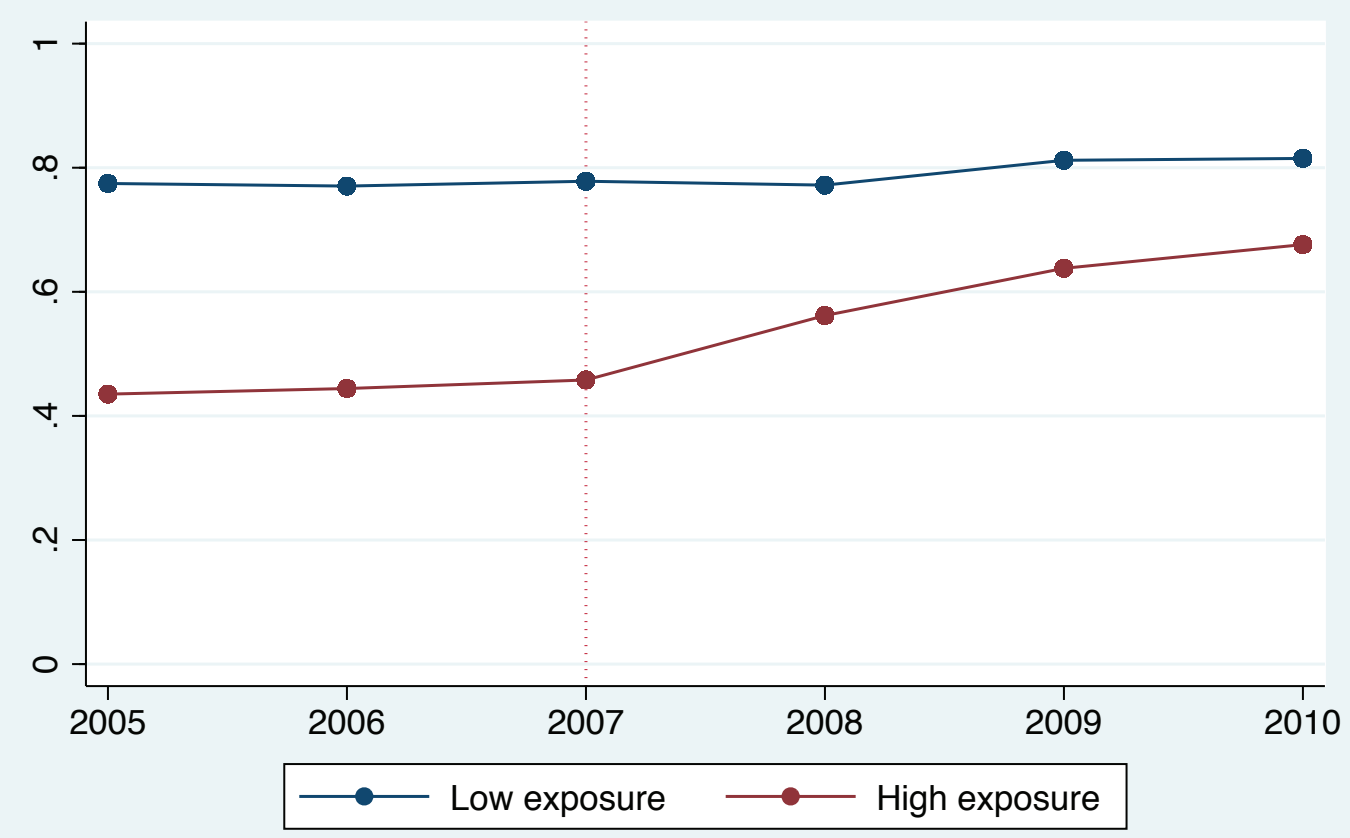

Notes: This figure plots trends in the use of formal-sector health providers in high- and low-exposure villages. Dotted line indicates when the ban went into effect. 
Figure 6

\section{Probability of a newborn death}

\section{A. Within the first week}

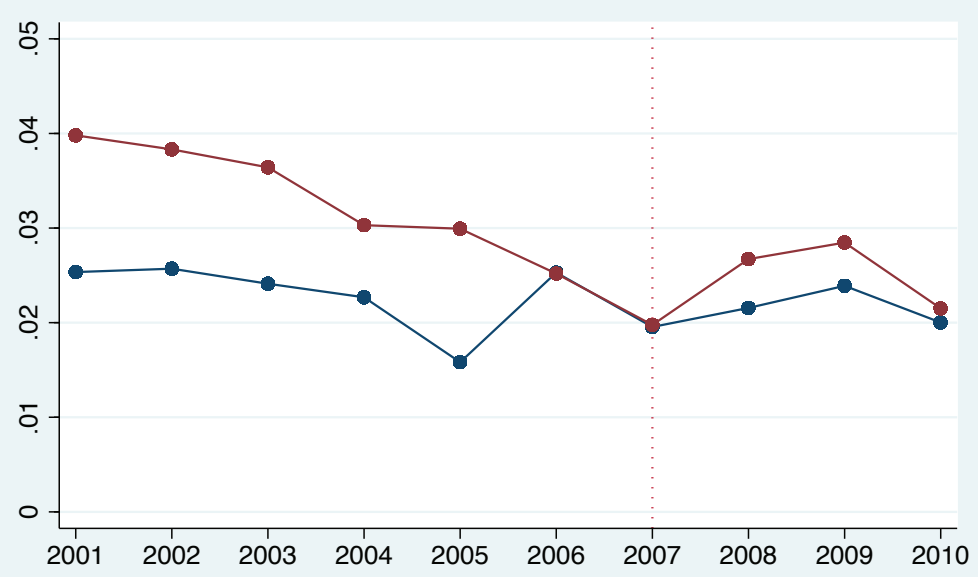

B. Within the first month

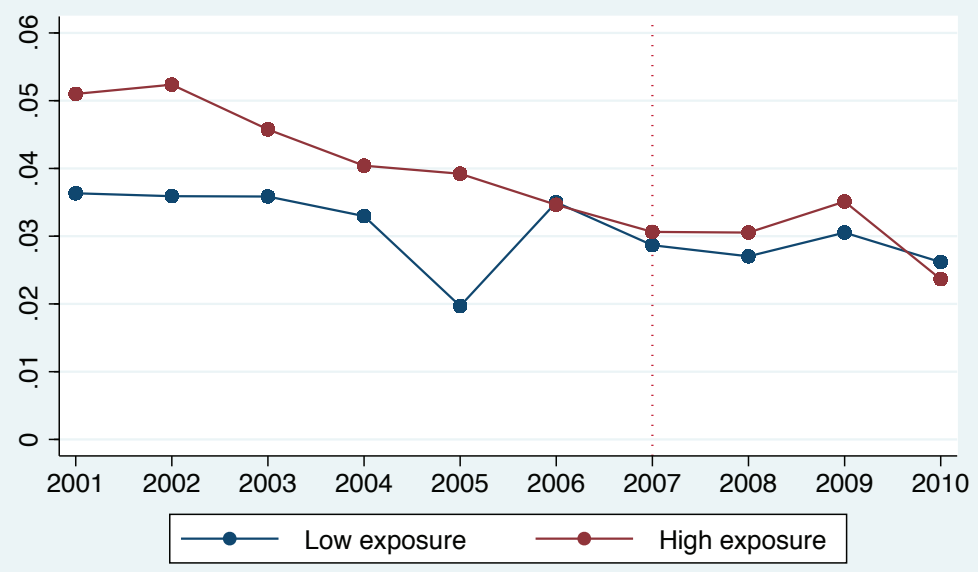

Notes: This figure plots trends in newborn mortality for singleton births between 2001 and 2010 in high- and low-exposure villages. Top figure shows mortality within the first week of life while bottom figure shows mortality within the first month. Dotted line indicates when the ban went into effect. 


\section{Are results robust to choice of percentile threshold?}

A. use of informal attendants

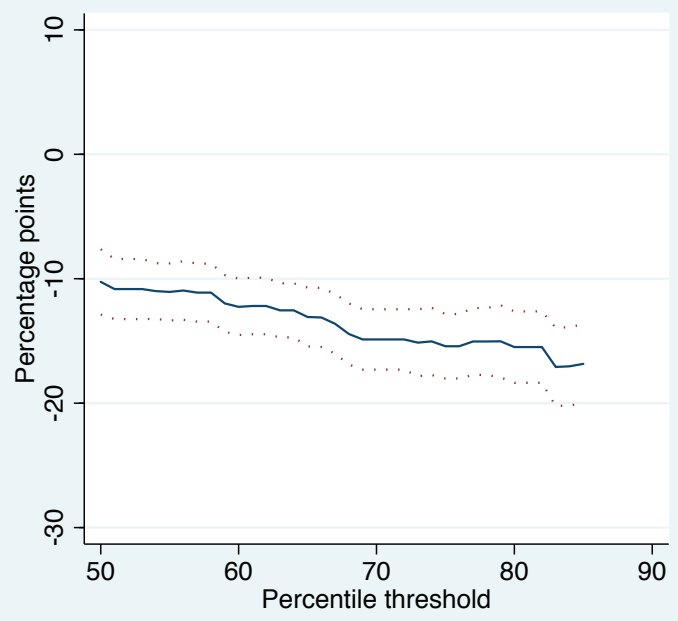

C. Deaths within the first week

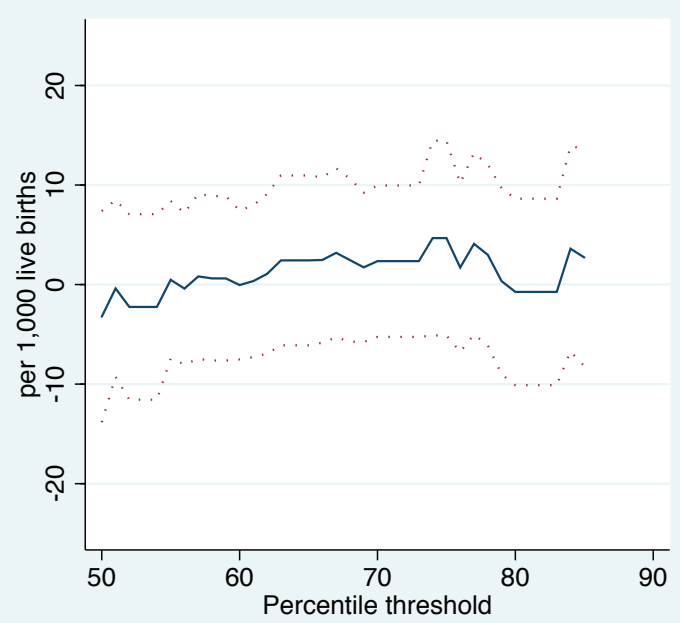

B. Use of formal sector providers

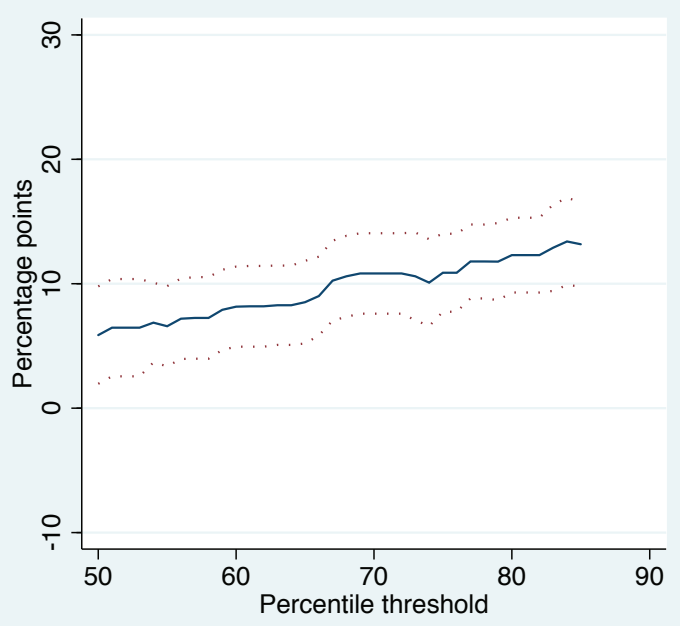

C. Deaths within the first month

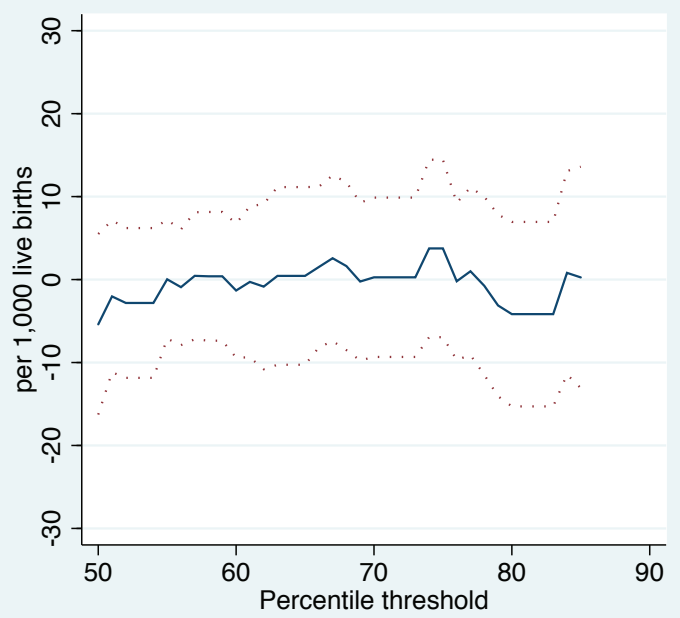

Notes: We examine the sensitivity of the key results to changes in the percentile threshold used in defining our exposure variable. Figure shows coefficient estimates and associated $95 \%$ confidence intervals obtained from difference-in-difference model specifications corresponding to Column 5 of Tables 5, 6, 8 and 9 . 
Figure 8

Distribution of births by quality of nearest health facility

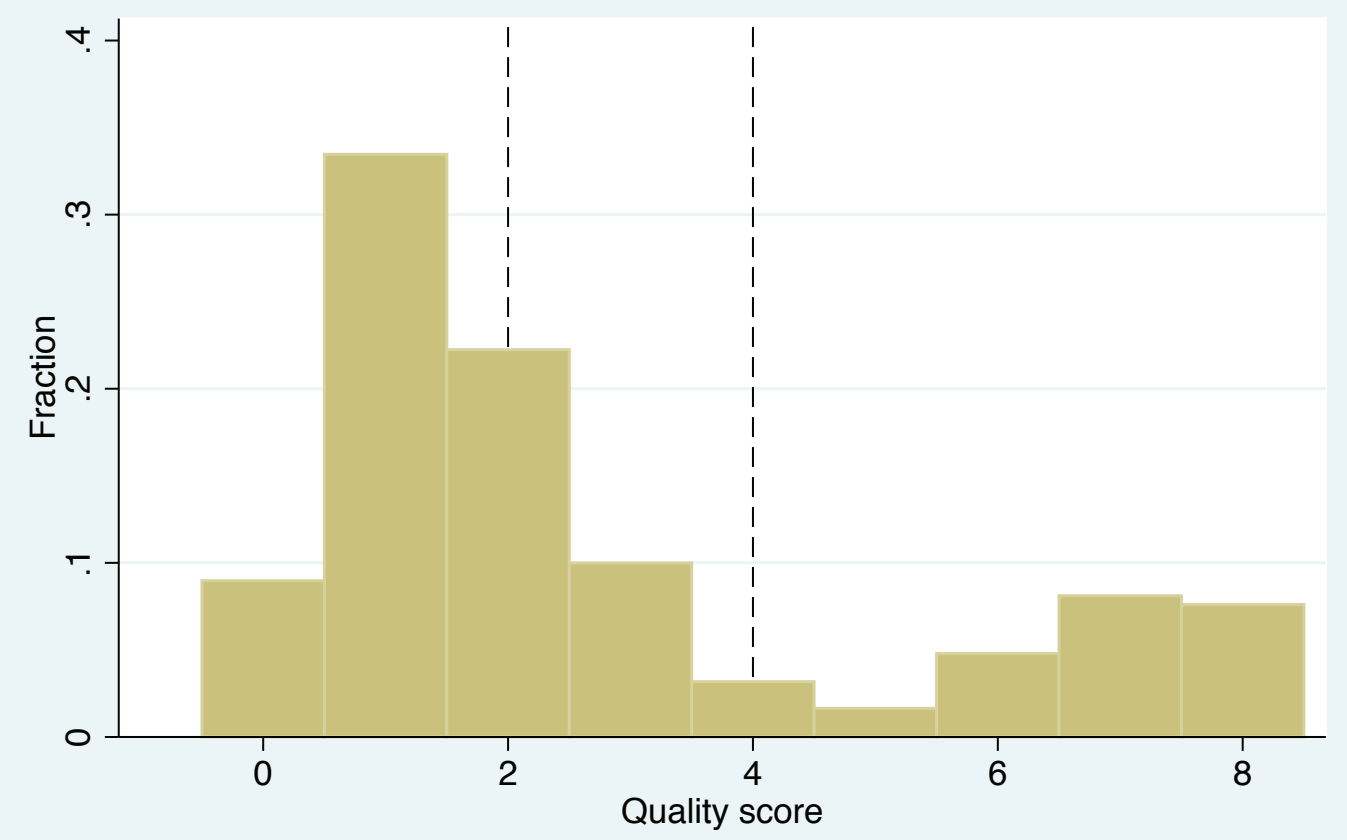

Notes: This figure shows the distribution of births by the quality score of the nearest health facility. The dotted lines indicate the $50^{\text {m }}$ and $75^{\text {m }}$ percentiles respectively. The set of indicators used in calculating the quality score are shown in Table 13. Each indicator is assigned a score of one and we sum the scores for each facility. 
Figure A.1

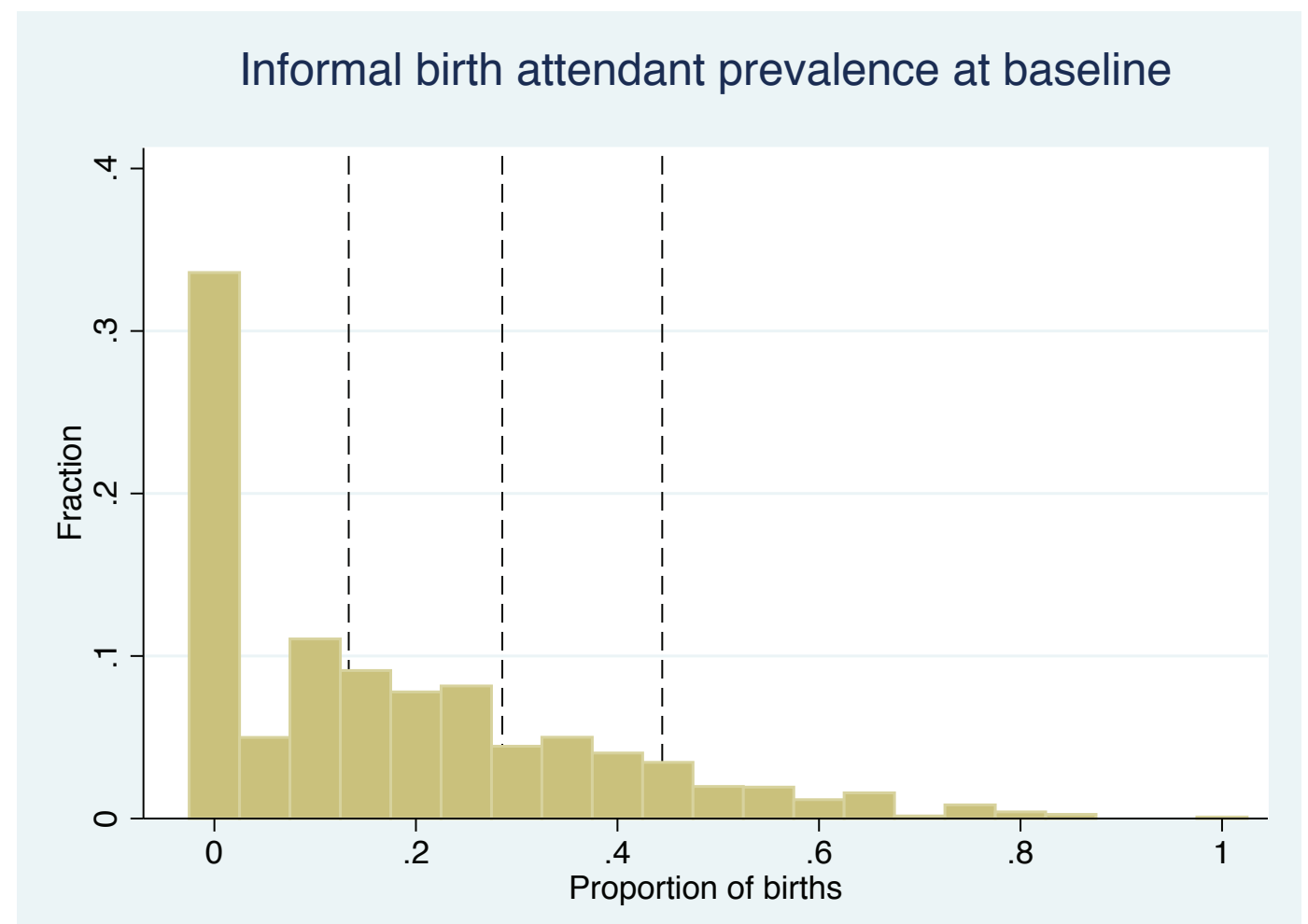

Notes: This figure plots the distribution of DHS clusters by baseline prevalence of informal birth attendant use. Dotted lines from left to right indicate the 50th, 75th, and 90th percentiles respectively. 
Table 1: Summary Statistics

Panel A: Women sample

\begin{tabular}{|c|c|c|c|}
\hline VARIABLES & Mean & SD & $\mathrm{N}$ \\
\hline \multicolumn{4}{|l|}{ Mother's age } \\
\hline $15-19$ & 0.07 & $26.0 \%$ & 13564 \\
\hline $20-24$ & $27.1 \%$ & $44.4 \%$ & 13564 \\
\hline $25-29$ & $27.5 \%$ & $44.7 \%$ & 13564 \\
\hline $30-34$ & $18.2 \%$ & $38.6 \%$ & 13564 \\
\hline $35-39$ & $12.0 \%$ & $32.5 \%$ & 13564 \\
\hline $40-44$ & $5.5 \%$ & $22.8 \%$ & 13564 \\
\hline $45-49$ & $2.5 \%$ & $15.5 \%$ & 13564 \\
\hline Spouse or partner & $85.5 \%$ & $35.2 \%$ & 13564 \\
\hline \multicolumn{4}{|l|}{ Religion } \\
\hline Christian & $84.4 \%$ & $36.3 \%$ & 13564 \\
\hline Muslim & $14.3 \%$ & $35.0 \%$ & 13564 \\
\hline Other religion & $1.3 \%$ & $11.3 \%$ & 13564 \\
\hline \multicolumn{4}{|l|}{ Mother's schooling } \\
\hline No education & $16.7 \%$ & $37.3 \%$ & 13564 \\
\hline Some Primary education & $67.0 \%$ & $47.0 \%$ & 13564 \\
\hline Some Secondary education & $15.4 \%$ & $36.1 \%$ & 13564 \\
\hline Higher education & $0.9 \%$ & $9.5 \%$ & 13564 \\
\hline \multicolumn{4}{|l|}{ Ethnicity } \\
\hline Chewa & $34.9 \%$ & $47.7 \%$ & 13564 \\
\hline Tumbuka & $8.7 \%$ & $28.2 \%$ & 13564 \\
\hline Lomwe & $15.8 \%$ & $36.5 \%$ & 13564 \\
\hline Tonga & $1.7 \%$ & $12.9 \%$ & 13564 \\
\hline Yao & $13.6 \%$ & $34.3 \%$ & 13564 \\
\hline Sena & $4.9 \%$ & $21.6 \%$ & 13564 \\
\hline Nkhonde & $1.0 \%$ & $10.1 \%$ & 13564 \\
\hline Ngoni & $12.1 \%$ & $32.6 \%$ & 13564 \\
\hline Other & $7.2 \%$ & $25.9 \%$ & 13564 \\
\hline \multicolumn{4}{|l|}{ Partner's schooling } \\
\hline No education & $11.0 \%$ & $31.3 \%$ & 13138 \\
\hline Primary education & $59.6 \%$ & $49.1 \%$ & 13138 \\
\hline Some Secondary education & $27.2 \%$ & $44.5 \%$ & 13138 \\
\hline Higher education & $2.1 \%$ & $14.5 \%$ & 13138 \\
\hline \multicolumn{4}{|l|}{ Household characteristics } \\
\hline Flush toilet & $1.5 \%$ & $12.0 \%$ & 13564 \\
\hline Have electricity & $7.9 \%$ & $27.0 \%$ & 13564 \\
\hline \multicolumn{4}{|l|}{ Other characteristics } \\
\hline Rural & $84.6 \%$ & $36.1 \%$ & 13564 \\
\hline Distance to nearest health facility $(\mathrm{km})$ & 4.89 & 3.41 & 13249 \\
\hline Northern region & $11.5 \%$ & $31.9 \%$ & 13564 \\
\hline Central region & $42.7 \%$ & $49.5 \%$ & 13564 \\
\hline Southern region & $45.9 \%$ & $49.8 \%$ & 13564 \\
\hline
\end{tabular}

Notes: The sample includes all resident women in the MDHS 2010 sample. 
Panel B: Birth sample

\begin{tabular}{lrrrrrr}
\hline & \multicolumn{2}{c}{ Pre-ban } & \multicolumn{3}{c}{ Post-ban } \\
VARIABLES & Mean & SD & N & Mean & SD & $N$ \\
\hline & & & & & & \\
Mother's age at birth & 25.6 & 6.7 & 9339 & 26.3 & 6.8 & 10341 \\
Birth order & 3.5 & 2.3 & 9339 & 3.6 & 2.3 & 10341 \\
Multiple pregnancy & $4.3 \%$ & $20.4 \%$ & 9339 & $4.3 \%$ & $20.2 \%$ & 10341 \\
Male birth & $48.9 \%$ & $50.0 \%$ & 9339 & $50.5 \%$ & $50.0 \%$ & 10341 \\
Young mother (age<18 years) & $12.7 \%$ & $33.3 \%$ & 9339 & $10.2 \%$ & $30.3 \%$ & 10341 \\
First birth & $21.4 \%$ & $41.0 \%$ & 9339 & $19.4 \%$ & $39.6 \%$ & 10341 \\
Number of prenatal visits & 3.7 & 1.4 & 3929 & 3.5 & 1.3 & 9525 \\
Use of formal care & $70.1 \%$ & $45.8 \%$ & 9277 & $75.7 \%$ & $42.9 \%$ & 10330 \\
Use of informal birth attendant & $17.7 \%$ & $38.2 \%$ & 9277 & $11.5 \%$ & $32.0 \%$ & 10330 \\
Child death within first month & $3.1 \%$ & $17.2 \%$ & 9339 & $3.2 \%$ & $17.6 \%$ & 9849 \\
Child death within first week & $2.3 \%$ & $14.9 \%$ & 9339 & $2.6 \%$ & $15.8 \%$ & 9849 \\
\hline
\end{tabular}

Notes: The sample includes all births to resident women in the MDHS 2010 sample. Information about prenatal visits is only collected for the most recent birth within the last five years hence the smaller sample size. To calculate newborn mortality, we excluded births that occurred in the month of, or the month preceding the month of interview in 2010. This was to ensure that all newborn infants were fully exposed to the neonatal period. 
Table 2: Test of parallel time trends

\begin{tabular}{lcccc}
\hline & $\begin{array}{c}(1) \\
\text { Birth attended } \\
\text { by informal } \\
\text { attendant }\end{array}$ & $\begin{array}{c}(2) \\
\text { Birth attended } \\
\text { by formal- } \\
\text { sector provider }\end{array}$ & $\begin{array}{c}(3) \\
\text { Child death } \\
\text { within the first } \\
\text { week }\end{array}$ & $\begin{array}{c}\text { Child death } \\
\text { within the first } \\
\text { month }\end{array}$ \\
\hline High exposure & & & & \\
Time Trend & 0.566 & -0.419 & 0.0402 & 0.0340 \\
High exposure x Time Trend & $(0.505)$ & $(0.572)$ & $(0.0439)$ & $(0.0537)$ \\
Constant & -0.000558 & 0.000560 & $-5.75 \mathrm{e}-05$ & $-0.000110^{*}$ \\
& $(0.000349)$ & $(0.000442)$ & $(4.30 \mathrm{e}-05)$ & $(5.58 \mathrm{e}-05)$ \\
& $\mathbf{0 . 0 0 0 3 8 8}$ & $\mathbf{0 . 0 0 0 1 7 5}$ & $\mathbf{- 6 . 5 2 e - 0 5}$ & $\mathbf{- 5 . 1 2 e - 0 5}$ \\
Observations & $\mathbf{( 0 . 0 0 0 9 0 2 )}$ & $\mathbf{( 0 . 0 0 1 0 2 )}$ & $\mathbf{( 8 . 2 1 e - 0 5 )}$ & $\mathbf{( 9 . 8 3 e - 0 5 )}$ \\
R-squared & $0.401^{*}$ & 0.459 & $0.0499 * *$ & $0.0860 * * *$ \\
& $(0.195)$ & -0.247 & $(0.0230)$ & $(0.0301)$ \\
\hline
\end{tabular}

Notes: Sample is all births prior to the ban. All regressions include district dummies. The DHS collects data on type of birth attendant for only births within the preceding five years but collects mortality data for all births hence the larger sample size in Columns 3 and 4 (we restrict the sample to all births within the last ten years). Standard errors in parentheses are clustered at the district level (there are 27 districts). ${ }^{* * *} p<0.01,{ }^{* *} p<0.05,{ }^{*} p<0.1$. 
Table 3: Characteristics of high and low exposure areas

\begin{tabular}{|c|c|c|c|c|c|c|}
\hline \multirow[b]{2}{*}{ VARIABLES } & \multicolumn{2}{|c|}{ Low-exposure } & \multicolumn{2}{|c|}{ High exposure } & \multirow[b]{2}{*}{ Difference } & \multirow[b]{2}{*}{$p$-value } \\
\hline & Mean & (SD) & Mean & (SD) & & \\
\hline \multicolumn{7}{|l|}{ Birth characteristics } \\
\hline Mother's age at birth & 25.5 & $(6.6)$ & 25.8 & (6.7) & 0.33 & 0.11 \\
\hline Twin birth & 0.04 & $(0.20)$ & 0.05 & $(0.22)$ & 0.01 & 0.27 \\
\hline Male birth & 0.49 & $(0.50)$ & 0.48 & $(0.50)$ & -0.01 & 1.00 \\
\hline Number of antenatal visits & 3.7 & $(1.4)$ & 3.7 & $(1.5)$ & 0.06 & 0.45 \\
\hline Received tetanus vaccination before birth & 0.89 & $(0.32)$ & 0.89 & $(0.31)$ & 0.00 & 0.85 \\
\hline \multicolumn{7}{|l|}{ Maternal characteristics } \\
\hline Number of children ever born & 3.8 & $(2.3)$ & 4.1 & (2.4) & 0.25 & 0.00 \\
\hline Mother's age at first birth & 18.5 & (2.9) & 18.5 & (2.9) & 0.04 & 0.48 \\
\hline Mother's age at first marriage & 17.4 & $(3.0)$ & 17.4 & (3.1) & -0.07 & 0.66 \\
\hline Christian & 0.84 & $(0.37)$ & 0.84 & $(0.37)$ & 0.00 & 0.57 \\
\hline Mother has no education & 0.17 & $(0.37)$ & 0.20 & $(0.40)$ & 0.03 & 0.08 \\
\hline Husband has no education & 0.11 & $(0.31)$ & 0.13 & $(0.34)$ & 0.02 & 0.11 \\
\hline Mother is unemployed & 0.24 & $(0.43)$ & 0.22 & $(0.42)$ & -0.02 & 0.47 \\
\hline \multicolumn{7}{|l|}{ Household characteristics } \\
\hline Household head is female & 0.21 & $(0.40)$ & 0.19 & $(0.40)$ & -0.01 & 0.25 \\
\hline Household size & 5.7 & $(2.2)$ & 5.7 & (2.1) & 0.02 & 0.73 \\
\hline Household has bicycle & 0.48 & $(0.50)$ & 0.53 & $(0.50)$ & 0.05 & 0.53 \\
\hline Household has electricity & 0.09 & $(0.28)$ & 0.03 & $(0.16)$ & -0.06 & 0.00 \\
\hline Household has radio & 0.11 & $(0.32)$ & 0.05 & $(0.21)$ & -0.07 & 0.00 \\
\hline Household belongs to poorest quintile & 0.20 & $(0.40)$ & 0.28 & $(0.45)$ & 0.08 & 0.00 \\
\hline \multicolumn{7}{|l|}{ Village characteristics } \\
\hline Rural location & 0.84 & $(0.37)$ & 0.91 & $(0.29)$ & 0.07 & 0.00 \\
\hline Northern region & 0.14 & $(0.34)$ & 0.06 & $(0.24)$ & -0.07 & 0.06 \\
\hline Central region & 0.38 & $(0.48)$ & 0.58 & $(0.49)$ & 0.20 & 0.00 \\
\hline Southern region & 0.49 & $(0.50)$ & 0.36 & $(0.48)$ & -0.12 & 0.03 \\
\hline Distance to nearest facility $(\mathrm{km})$ & 4.4 & (3.1) & 6.58 & (3.7) & 2.17 & 0.00 \\
\hline
\end{tabular}

Notes: This table compares characteristics of high and low-exposure areas. $p$-values are from a test of equality of means. 
Table 4: Is treatment correlated with observables?

\begin{tabular}{|c|c|c|c|c|c|c|c|c|c|}
\hline & (1) & (2) & (3) & (4) & (5) & (6) & (7) & (8) & (9) \\
\hline VARIABLES & Twin birth & Male birth & First birth & $\begin{array}{l}\text { Young } \\
\text { mother }\end{array}$ & $\begin{array}{l}\text { Number of } \\
\text { children } \\
\text { ever born }\end{array}$ & $\begin{array}{l}\text { Mother's age } \\
\text { at first birth }\end{array}$ & $\begin{array}{l}\text { Mother is } \\
\text { Christian }\end{array}$ & $\begin{array}{c}\text { No } \\
\text { education } \\
\text { (mother) }\end{array}$ & $\begin{array}{c}\text { No } \\
\text { education } \\
\text { (spouse) }\end{array}$ \\
\hline \multirow[t]{2}{*}{ High Exposure } & 0.0089 & 0.00306 & -0.0095 & -0.000565 & $0.237 * * *$ & -0.00518 & 0.0172 & $0.0362^{* * *}$ & 0.00916 \\
\hline & -0.00578 & -0.0122 & -0.00854 & -0.00758 & -0.07 & -0.113 & -0.015 & -0.0113 & -0.00889 \\
\hline \multirow[t]{2}{*}{ Post } & 0.00852 & 0.00697 & $-0.0209 *$ & -0.00985 & -0.00716 & -0.143 & -0.00901 & $0.0228 *$ & 0.00111 \\
\hline & -0.00858 & -0.0134 & -0.0112 & -0.00737 & -0.0616 & -0.0949 & -0.00953 & -0.0123 & -0.00908 \\
\hline \multirow[t]{2}{*}{ High Exposure x Post } & -0.00693 & -0.00823 & 0.00431 & 0.00415 & -0.0992 & -0.0479 & -0.00602 & -0.0164 & 0.00414 \\
\hline & -0.00744 & -0.0156 & -0.0122 & -0.00865 & -0.0713 & -0.0641 & -0.00817 & -0.00994 & -0.00847 \\
\hline \multirow[t]{2}{*}{ Constant } & $0.549 * * *$ & $0.935 * * *$ & -0.187 & $0.477 * * *$ & $17.16 * * *$ & $15.01 * * *$ & $0.868 * * *$ & $0.479 * * *$ & -0.0109 \\
\hline & -0.12 & -0.17 & -0.157 & -0.104 & -0.795 & -1.294 & -0.121 & -0.163 & -0.121 \\
\hline Observations & 19680 & 19680 & 19680 & 19680 & 19680 & 19680 & 19680 & 19680 & 19192 \\
\hline \multirow[t]{2}{*}{ R-squared } & 0.009 & 0.003 & 0.005 & 0.008 & 0.03 & 0.021 & 0.355 & 0.068 & 0.039 \\
\hline & $\begin{array}{c}\text { (10) } \\
\text { Unemploy } \\
\text { ed }\end{array}$ & $\begin{array}{c}(11) \\
\text { Household } \\
\text { head is } \\
\text { female }\end{array}$ & $\begin{array}{c}\text { (12) } \\
\text { Household } \\
\text { size }\end{array}$ & $\begin{array}{c}\text { (13) } \\
\text { Househol } \\
\text { d has } \\
\text { bicycle }\end{array}$ & $\begin{array}{c}\text { (14) } \\
\text { Household } \\
\text { has } \\
\text { electricity }\end{array}$ & $\begin{array}{c}\text { Household } \\
\text { has radio }\end{array}$ & $\begin{array}{c}\text { (16) } \\
\text { Poorest } \\
\text { wealth } \\
\text { quintile }\end{array}$ & $\begin{array}{c}\text { (17) } \\
\text { Rural } \\
\text { location } \\
\end{array}$ & $\begin{array}{c}(18) \\
\text { Distance to } \\
\text { nearest } \\
\text { facility }\end{array}$ \\
\hline \multirow[t]{2}{*}{ High Exposure } & -0.0155 & -0.00487 & 0.00358 & 0.0149 & $-0.0385 * * *$ & $-0.0479 * * *$ & $0.0627^{* * *}$ & $0.0580 * * *$ & $2.067 * * *$ \\
\hline & -0.0173 & -0.014 & -0.0679 & -0.0246 & -0.00998 & -0.0113 & -0.0143 & -0.0159 & -0.296 \\
\hline \multirow[t]{2}{*}{ Post } & $-0.0227 * *$ & -0.0122 & -0.0784 & 0.0122 & -0.000171 & $-0.0200 * * *$ & -0.0155 & 0.00227 & -0.0321 \\
\hline & -0.00914 & -0.0139 & -0.0578 & -0.0111 & -0.00514 & -0.00683 & -0.0102 & -0.00766 & -0.1 \\
\hline \multirow[t]{2}{*}{ High Exposure x Post } & -0.00356 & 0.00421 & -0.0965 & -0.00849 & -0.00296 & 0.00277 & 0.00149 & -0.00327 & -0.014 \\
\hline & -0.0116 & -0.0119 & -0.0629 & -0.0151 & -0.00567 & -0.00755 & -0.0148 & -0.00607 & -0.067 \\
\hline \multirow[t]{2}{*}{ Constant } & $-0.929 * * *$ & -0.259 & $10.56 * * *$ & $1.737 * * *$ & $-0.183 * * *$ & $-0.313 * * *$ & $-0.431 * * *$ & $0.971 * * *$ & $5.341 * * *$ \\
\hline & -0.137 & -0.177 & -0.765 & -0.152 & -0.0642 & -0.0923 & -0.134 & -0.102 & -1.293 \\
\hline Observations & 19680 & 19680 & 19680 & 19680 & 19680 & 19680 & 19680 & 19680 & 19211 \\
\hline R-squared & 0.086 & 0.022 & 0.028 & 0.043 & 0.062 & 0.046 & 0.053 & 0.192 & 0.242 \\
\hline
\end{tabular}

Notes: All columns include district and month $\mathrm{x}$ year fixed effects. Standard errors in parentheses are clustered at the district level (there are 27 districts). ${ }^{* * *} \mathrm{p}<0.01,{ }^{* *}$ $\mathrm{p}<0.05, * \mathrm{p}<0.1$. 
Table 5: What was the effect of the ban on the use of informal birth attendants?

\begin{tabular}{|c|c|c|c|c|c|c|}
\hline \multirow[b]{2}{*}{ VARIABLES } & \multicolumn{6}{|c|}{ Birth attendant is informal attendant } \\
\hline & (1) & $(2)$ & (3) & $(4)$ & (5) & $(6)$ \\
\hline High Exposure x Post & $\begin{array}{c}-0.189 * * * \\
(0.0146)\end{array}$ & $\begin{array}{c}-0.190 * * * \\
(0.0130)\end{array}$ & $\begin{array}{c}-0.184 * * * \\
(0.0141)\end{array}$ & $\begin{array}{c}-0.187 * * * \\
(0.0144)\end{array}$ & $\begin{array}{c}-0.154 * * * \\
(0.0126)\end{array}$ & $\begin{array}{c}-0.188 * * * \\
(0.0146)\end{array}$ \\
\hline High Exposure & $\begin{array}{c}0.344 * * * \\
(0.0143)\end{array}$ & $\begin{array}{c}0.321 * * * \\
(0.0131)\end{array}$ & $\begin{array}{c}0.318^{* * *} \\
(0.0123)\end{array}$ & $\begin{array}{c}0.320 * * * \\
(0.0127)\end{array}$ & $\begin{array}{c}0.267 * * * \\
(0.0110)\end{array}$ & \\
\hline Post & & & & $\begin{array}{c}0.0134 \\
(0.0667)\end{array}$ & $\begin{array}{c}-0.0655 \\
(0.0908)\end{array}$ & $\begin{array}{c}-0.000915 \\
(0.0679)\end{array}$ \\
\hline Male birth & & $\begin{array}{l}-0.00557 \\
(0.00440)\end{array}$ & & & & \\
\hline Multiple pregnancy & & $\begin{array}{l}-0.0121 \\
(0.0149)\end{array}$ & & & & \\
\hline Birth order & & $\begin{array}{c}0.00161 \\
(0.00250)\end{array}$ & & & & \\
\hline Mother's education: primary school ${ }^{1}$ & & $\begin{array}{l}-0.0169 * \\
(0.00945)\end{array}$ & & & & \\
\hline Mother's education: secondary ${ }^{1}$ & & $\begin{array}{c}-0.0486^{* * *} \\
(0.0148)\end{array}$ & & & & \\
\hline Mother's education: tertiary ${ }^{1}$ & & $\begin{array}{c}-0.0718^{* *} \\
(0.0269)\end{array}$ & & & & \\
\hline Married or living with partner & & $\begin{array}{c}0.0165^{*} \\
(0.00952)\end{array}$ & & & & \\
\hline Mother's age $=20-24^{2}$ & & $\begin{array}{l}0.00799 \\
(0.0102)\end{array}$ & & & & \\
\hline Mother's age $=25-29^{2}$ & & $\begin{array}{l}0.00421 \\
(0.0123)\end{array}$ & & & & \\
\hline Mother's age $=30-34^{2}$ & & $\begin{array}{r}-0.00785 \\
(0.0131)\end{array}$ & & & & \\
\hline Mother's age $=35-39^{2}$ & & $\begin{array}{l}-0.0118 \\
(0.0147)\end{array}$ & & & & \\
\hline Mother's age $=40-44^{2}$ & & $\begin{array}{l}-0.0164 \\
(0.0254)\end{array}$ & & & & \\
\hline Mother's age $=45-49^{2}$ & & $\begin{array}{l}-0.0368 \\
(0.0508)\end{array}$ & & & & \\
\hline Religion $=$ Christian & & $\begin{array}{l}-0.0283 \\
(0.0348)\end{array}$ & & & & \\
\hline Religion = Muslim & & $\begin{array}{c}-0.0371 \\
(0.0395)\end{array}$ & & & & \\
\hline Spouse's education: primary school ${ }^{1}$ & & $\begin{array}{l}-0.00223 \\
(0.00977)\end{array}$ & & & & \\
\hline Spouse's education: secondary school ${ }^{1}$ & & $\begin{array}{c}-0.00884 \\
(0.00958)\end{array}$ & & & & \\
\hline
\end{tabular}


Spouse's education: tertiary school ${ }^{1}$

Wealth quintile $2^{3}$

Wealth quintile $3^{3}$

Wealth quintile $4^{3}$

Wealth quintile $5^{3}$

Rural location

Distance to health facility

Constant

Controls

Controls $x$ Post

District-specific trend

Trimmed data

Cluster Fixed Effects
$-0.0273$

(0.0173)

$-0.0167$

(0.0113)

$-0.0224 * *$

(0.0103)

$-0.0461 * * *$

(0.0124)

$-0.0570 * * *$

(0.0110)

$0.0224 * *$

$(0.00824)$

$0.00586 * * *$

(0.00122)

$0.0411 * * * \quad 0.0537$

$0.0512 \quad 1.848^{* * *}$

$3.525^{* * *}$

$0.265^{* * *}$

(0.00204)

(0.0415)

(0.0410)

(0.284)

(0.440)

(0.0637)

$\begin{array}{llllll}\text { No } & \text { Yes } & \text { Yes } & \text { Yes } & \text { Yes } & \text { Yes } \\ \text { No } & \text { No } & \text { Yes } & \text { Yes } & \text { Yes } & \text { Yes } \\ \text { No } & \text { No } & \text { No } & \text { Yes } & \text { Yes } & \text { No } \\ \text { No } & \text { No } & \text { No } & \text { No } & \text { Yes } & \text { No } \\ \text { No } & \text { No } & \text { No } & \text { No } & \text { No } & \text { Yes }\end{array}$

Observations

19,607

18,673

18,673

18,673

12,491

18,673

R-squared

0.138

0.149

0.150

0.148

0.113

0.209

Notes: Dependent variable is an indicator for a birth attended by an informal birth attendant. Controls include an indicator for male births, an indicator for a multiple birth, birth order, dummies for mother's level of schooling, dummies for mother's age at birth, an indicator for women who are married or living with a partner, dummies for ethnicity and religion, dummies for the partner's educational attainment, distance to the nearest health facility, wealth quintile dummies, and a rural-urban indicator. Each column includes district and year $x$ month fixed effects. Full set of coefficients not shown to conserve space. In Column 5 , we exclude villages with baseline prevalence of 0 or 1 to account for 'floor' and 'ceiling' effects. Column 6 is equivalent to Column 3 except that district fixed effects have been replaced with cluster fixed effects. Post=1 if birth occurs after December 2007. Standard errors in parentheses are clustered at the district level (there are 27 districts). $* * * \quad p<0.01, * * \quad p<0.05, * \quad p<0.1$ ${ }^{1}$ Omitted group is no schooling; ${ }^{2}$ Omitted group is 19 and younger; ${ }^{3}$ Omitted group is poorest quintile 
Table 6: What was the effect of the ban on the use of formal care?

\begin{tabular}{|c|c|c|c|c|c|c|}
\hline \multirow[b]{2}{*}{ VARIABLES } & \multicolumn{6}{|c|}{ Birth attendant is formal sector provider } \\
\hline & (1) & $(2)$ & (3) & (4) & $(5)$ & (6) \\
\hline \multirow[t]{2}{*}{ High Exposure x Post } & $0.145^{* * *}$ & $0.144 * * *$ & $0.143 * * *$ & $0.146 * * *$ & $0.109 * * *$ & $0.150 * * *$ \\
\hline & $(0.0157)$ & $(0.0136)$ & $(0.0153)$ & $(0.0152)$ & $(0.0152)$ & $(0.0165)$ \\
\hline \multirow[t]{2}{*}{ High Exposure } & $-0.317 * * *$ & $-0.270 * * *$ & $-0.269 * * *$ & $-0.271 * * *$ & $-0.206 * * *$ & \\
\hline & $(0.0177)$ & $(0.0150)$ & $(0.0152)$ & $(0.0149)$ & $(0.0155)$ & \\
\hline \multirow[t]{2}{*}{ Post } & & & & 0.0660 & 0.132 & 0.00746 \\
\hline & & & & $(0.0794)$ & $(0.0889)$ & $(0.0974)$ \\
\hline \multirow[t]{2}{*}{ Male birth } & & 0.00932 & & & & \\
\hline & & $(0.00591)$ & & & & \\
\hline \multirow[t]{2}{*}{ Multiple pregnancy } & & 0.0223 & & & & \\
\hline & & $(0.0217)$ & & & & \\
\hline \multirow[t]{2}{*}{ Birth order } & & $-0.0172 * * *$ & & & & \\
\hline & & $(0.00306)$ & & & & \\
\hline \multirow[t]{2}{*}{ Mother's education: primary school ${ }^{1}$} & & $0.0587^{* * *}$ & & & & \\
\hline & & $(0.0106)$ & & & & \\
\hline \multirow[t]{2}{*}{ Mother's education: secondary ${ }^{1}$} & & $0.113^{* * *}$ & & & & \\
\hline & & $(0.0169)$ & & & & \\
\hline \multirow[t]{2}{*}{ Mother's education: tertiary school ${ }^{1}$} & & $0.113^{* * *}$ & & & & \\
\hline & & $(0.0260)$ & & & & \\
\hline \multirow[t]{2}{*}{ Married or living with partner } & & -0.00643 & & & & \\
\hline & & $(0.0138)$ & & & & \\
\hline \multirow[t]{2}{*}{ Mother's age $=20-24^{2}$} & & $-0.0386 * * *$ & & & & \\
\hline & & $(0.0107)$ & & & & \\
\hline \multirow[t]{2}{*}{ Mother's age $=25-29^{2}$} & & $-0.0233^{*}$ & & & & \\
\hline & & $(0.0123)$ & & & & \\
\hline \multirow[t]{2}{*}{ Mother's age $=30-34^{2}$} & & -0.00217 & & & & \\
\hline & & $(0.0157)$ & & & & \\
\hline \multirow[t]{2}{*}{ Mother's age $=35-39^{2}$} & & 0.0168 & & & & \\
\hline & & $(0.0227)$ & & & & \\
\hline \multirow[t]{2}{*}{ Mother's age $=40-44^{2}$} & & $0.0767^{* *}$ & & & & \\
\hline & & $(0.0304)$ & & & & \\
\hline \multirow[t]{2}{*}{ Mother's age $=45-49^{2}$} & & -0.00218 & & & & \\
\hline & & $(0.0673)$ & & & & \\
\hline \multirow[t]{2}{*}{ Religion $=$ Christian } & & $0.148 * * *$ & & & & \\
\hline & & $(0.0372)$ & & & & \\
\hline \multirow[t]{2}{*}{ Religion $=$ Muslim } & & $0.150 * * *$ & & & & \\
\hline & & $(0.0422)$ & & & & \\
\hline \multirow[t]{2}{*}{ Spouse's education: primary school ${ }^{1}$} & & 0.0117 & & & & \\
\hline & & $(0.0124)$ & & & & \\
\hline Spouse's education: secondary ${ }^{1}$ & & $\begin{array}{c}0.0464 * * * \\
(0.0119)\end{array}$ & & & & \\
\hline
\end{tabular}


Spouse's education: tertiary school ${ }^{1}$

Wealth quintile $2^{3}$

Wealth quintile $3^{3}$

Wealth quintile $4^{3}$

Wealth quintile $5^{3}$

Rural location

Distance to health facility

Constant

Controls

Controls $\mathrm{x}$ Post

District-specific trend

Trimmed data

Cluster Fixed Effects
$0.0962 * * *$

(0.0237)

$0.0278^{* *}$

(0.0116)

$0.0395 * * *$

(0.0127)

$0.0831 * * *$

(0.0139)

$0.122^{* * *}$

(0.0165)

$-0.0191$

(0.0165)

$-0.0110 * * *$

(0.00246)
$0.730 * * *$

(0.0429)
$-2.433^{* * *}$

(0.479)
$0.446 * * *$

(0.0995)

$$
\text { (0.00257) (0.0431) }
$$

Yes
Yes
No
No
No

Yes
Yes
Yes
No
No

$\begin{array}{cc}\text { Yes } & \text { Yes } \\ \text { Yes } & \text { Yes } \\ \text { Yes } & \text { No } \\ \text { Yes } & \text { No } \\ \text { No } & \text { Yes }\end{array}$

Observations

19,607

18,673

18,673

18,673

12,491

18,673

0.088

0.132

0.134

0.131

0.104

0.218

Notes: Dependent variable is an indicator for a birth attended by a formal-sector provider. Controls include an indicator for male births, an indicator for a multiple birth, birth order, dummies for mother's level of schooling, dummies for mother's age at birth, an indicator for women who are married or living with a partner, dummies for ethnicity and religion, dummies for the partner's educational attainment, distance to the nearest health facility, wealth quintile dummies, and a rural-urban indicator. Each column includes district and year x month fixed effects. Full set of coefficients not shown to conserve space. In Column 5 , we exclude villages with baseline prevalence of 0 or 1 to account for 'floor' and 'ceiling' effects. Column 6 is equivalent to Column 3 except that district fixed effects have been replaced with cluster fixed effects. Post=1 if birth occurs after December 2007. Standard errors in parentheses are clustered at the district level (there are 27 districts). $* * * p<0.01, * * p<0.05, * p<0.1$

${ }^{1}$ Omitted group is no schooling; ${ }^{2}$ Omitted group is 19 and younger; ${ }^{3}$ Omitted group is poorest quintile 
Table 7: What was the effect of the ban on the use of other substitutes?

\begin{tabular}{|c|c|c|c|c|c|c|}
\hline \multirow[b]{2}{*}{ VARIABLES } & \multicolumn{6}{|c|}{ Birth attendant is a relative or friend } \\
\hline & (1) & $(2)$ & (3) & (4) & (5) & (6) \\
\hline \multirow[t]{2}{*}{ High Exposure x Post } & $0.0414 * * *$ & $0.0417 * * *$ & $0.0364 * * *$ & $0.0366 * * *$ & $0.0389 * * *$ & $0.0351 * * *$ \\
\hline & $(0.00694)$ & $(0.00725)$ & $(0.00863)$ & $(0.00918)$ & $(0.0110)$ & $(0.00962)$ \\
\hline \multirow[t]{2}{*}{ High Exposure } & $-0.0256 * * *$ & $-0.0424 * * *$ & $-0.0396 * * *$ & $-0.0399 * * *$ & $-0.0496 * * *$ & \\
\hline & $(0.00836)$ & $(0.00933)$ & $(0.00982)$ & $(0.0101)$ & $(0.0123)$ & \\
\hline \multirow[t]{2}{*}{ Post } & & & & -0.0476 & -0.0367 & 0.121 \\
\hline & & & & $(0.0543)$ & $(0.0812)$ & $(0.0812)$ \\
\hline \multirow[t]{2}{*}{ Constant } & $0.105^{* * *}$ & $0.186 * * *$ & $0.184 * * *$ & $0.750 * * *$ & 0.251 & $0.202 * * *$ \\
\hline & $(0.00151)$ & $(0.0542)$ & $(0.0536)$ & $(0.236)$ & (0.329) & $(0.0642)$ \\
\hline Observations & 19,607 & 18,673 & 18,673 & 18,673 & 12,491 & 18,673 \\
\hline \multirow[t]{2}{*}{ R-squared } & 0.022 & 0.041 & 0.042 & 0.039 & 0.042 & 0.133 \\
\hline & \multicolumn{6}{|c|}{ Birth was unattended } \\
\hline \multirow[t]{2}{*}{ High Exposure $x$ Post } & 0.00281 & 0.00322 & 0.00334 & 0.00247 & 0.00541 & 0.00116 \\
\hline & $(0.00512)$ & $(0.00491)$ & $(0.00493)$ & $(0.00557)$ & $(0.00543)$ & $(0.00518)$ \\
\hline \multirow[t]{2}{*}{ High Exposure } & 0.000257 & $-0.00614^{*}$ & -0.00622 & -0.00629 & $-0.00931 *$ & \\
\hline & (0.00338) & (0.00339) & $(0.00369)$ & (0.00393) & $(0.00493)$ & \\
\hline \multirow[t]{2}{*}{ Post } & & & & 0.0110 & 0.00680 & -0.0164 \\
\hline & & & & $(0.0474)$ & $(0.0572)$ & $(0.0513)$ \\
\hline \multirow[t]{2}{*}{ Constant } & $0.0306 * * *$ & 0.0184 & 0.0173 & -0.0440 & -0.234 & 0.0319 \\
\hline & $(0.000623)$ & $(0.0267)$ & $(0.0265)$ & $(0.158)$ & $(0.200)$ & $(0.0346)$ \\
\hline Controls & No & Yes & Yes & Yes & Yes & Yes \\
\hline Controls $\mathrm{x}$ Post & No & No & Yes & Yes & Yes & Yes \\
\hline District-specific trend & No & No & No & Yes & Yes & No \\
\hline Trimmed data & No & No & No & No & Yes & No \\
\hline Cluster Fixed Effects & No & No & No & No & No & Yes \\
\hline Observations & 19,607 & 18,673 & 18,673 & 18,673 & 12,491 & 18,673 \\
\hline R-squared & 0.009 & 0.033 & 0.034 & 0.033 & 0.038 & 0.097 \\
\hline
\end{tabular}

Notes: In Panel A (top) the dependent variable is an indicator for a birth attended by a relative or friend while in Panel B (bottom), the dependent variable is an indicator for an unattended birth. Controls include an indicator for male births, an indicator for a multiple birth, birth order, dummies for mother's level of schooling, dummies for mother's age at birth, an indicator for women who are married or living with a partner, dummies for ethnicity and religion, dummies for the partner's educational attainment, distance to the nearest health facility, wealth quintile dummies, and a rural-urban indicator. Each column includes district and year $\mathrm{x}$ month fixed effects. Full set of coefficients not shown to conserve space. In Column 5, we exclude villages with baseline prevalence of 0 or 1 to account for 'floor' and 'ceiling' effects. Column 6 is equivalent to Column 3 except that district fixed effects have been replaced with cluster fixed effects. Post 1 if birth occurs after December 2007. Standard errors in parentheses are clustered at the district level (there are 27 districts). ${ }^{* * *} p<0.01$, ** $p<0.05, * p<0.1$ 
Table 8: What was the effect of the ban on early newborn deaths (deaths in the first week)?

\begin{tabular}{|c|c|c|c|c|c|c|}
\hline \multirow[b]{2}{*}{ VARIABLES } & \multicolumn{6}{|c|}{ Child death within the first week } \\
\hline & (1) & $(2)$ & (3) & $(4)$ & (5) & $(6)$ \\
\hline \multirow[t]{2}{*}{ High Exposure x Post } & -2.939 & -2.742 & 0.319 & -0.645 & 1.712 & -0.344 \\
\hline & $(3.500)$ & $(3.530)$ & (3.669) & $(3.706)$ & (4.121) & (3.508) \\
\hline \multirow[t]{2}{*}{ High Exposure } & $5.311 * *$ & $5.383^{*}$ & 4.528 & 4.661 & 2.850 & \\
\hline & $(2.465)$ & $(2.812)$ & $(2.854)$ & $(2.912)$ & (3.380) & \\
\hline \multirow{2}{*}{ Post } & & & & -25.62 & -33.96 & -13.10 \\
\hline & & & & $(15.37)$ & $(20.75)$ & $(27.30)$ \\
\hline \multirow[t]{2}{*}{ Male birth } & & $6.929 * * *$ & & & & \\
\hline & & $(1.677)$ & & & & \\
\hline \multirow[t]{2}{*}{ First birth } & & $14.01^{* * *}$ & & & & \\
\hline & & $(2.411)$ & & & & \\
\hline \multirow[t]{2}{*}{ Young mother } & & $9.320 * *$ & & & & \\
\hline & & $(3.494)$ & & & & \\
\hline \multirow[t]{2}{*}{ Mother's education: primary school ${ }^{1}$} & & $3.678^{* *}$ & & & & \\
\hline & & $(1.638)$ & & & & \\
\hline \multirow[t]{2}{*}{ Mother's education: secondary school ${ }^{1}$} & & 1.005 & & & & \\
\hline & & $(2.456)$ & & & & \\
\hline \multirow[t]{2}{*}{ Mother's education: tertiary school ${ }^{1}$} & & 13.82 & & & & \\
\hline & & $(8.434)$ & & & & \\
\hline \multirow[t]{2}{*}{ Married or living with partner } & & 1.018 & & & & \\
\hline & & $(2.244)$ & & & & \\
\hline \multirow[t]{2}{*}{ Religion $=$ Christian } & & -1.801 & & & & \\
\hline & & $(5.575)$ & & & & \\
\hline \multirow[t]{2}{*}{ Religion = Muslim } & & 5.351 & & & & \\
\hline & & $(5.422)$ & & & & \\
\hline \multirow[t]{2}{*}{ Spouse's education: primary school ${ }^{1}$} & & -2.423 & & & & \\
\hline & & $(2.571)$ & & & & \\
\hline \multirow[t]{2}{*}{ Spouse's education: secondary school ${ }^{1}$} & & $-8.463 * *$ & & & & \\
\hline & & $(3.428)$ & & & & \\
\hline \multirow[t]{2}{*}{ Spouse's education: tertiary school ${ }^{1}$} & & $-16.49 * * *$ & & & & \\
\hline & & $(3.580)$ & & & & \\
\hline \multirow[t]{2}{*}{ Wealth quintile 2} & & 3.061 & & & & \\
\hline & & $(2.957)$ & & & & \\
\hline \multirow[t]{2}{*}{ Wealth quintile 3} & & 2.151 & & & & \\
\hline & & $(2.580)$ & & & & \\
\hline \multirow[t]{2}{*}{ Wealth quintile 4} & & $4.776^{*}$ & & & & \\
\hline & & $(2.701)$ & & & & \\
\hline \multirow[t]{2}{*}{ Wealth quintile 5} & & 4.705 & & & & \\
\hline & & $(3.533)$ & & & & \\
\hline \multirow[t]{2}{*}{ Rural location } & & 1.454 & & & & \\
\hline & & (3.159) & & & & \\
\hline Distance to health facility & & -0.166 & & & & \\
\hline
\end{tabular}




$\begin{array}{lcccccc}\text { Constant } & 21.39 * * * & 8.271 & 8.075 & 133.3 * * * & * & 5.029 \\ & (0.414) & (9.116) & (9.053) & (34.58) & (35.83) & (14.15) \\ & & & & & & \\ & \text { No } & \text { Yes } & \text { Yes } & \text { Yes } & \text { Yes } & \text { Yes } \\ \text { Controls } & \text { No } & \text { No } & \text { Yes } & \text { Yes } & \text { Yes } & \text { Yes } \\ \text { Controls x Post } & \text { No } & \text { No } & \text { No } & \text { Yes } & \text { Yes } & \text { No } \\ \text { District-specific trend } & \text { No } & \text { No } & \text { No } & \text { No } & \text { Yes } & \text { No } \\ \text { Trimmed data } & \text { No } & \text { No } & \text { No } & \text { No } & \text { No } & \text { Yes } \\ \text { Cluster Fixed Effects } & & & & & & \\ & 35,246 & 33,748 & 33,748 & 33,748 & 22,317 & 33,748 \\ \text { Observations } & 0.005 & 0.010 & 0.010 & 0.008 & 0.009 & 0.037 \\ \text { R-squared } & & & & & & \end{array}$

Notes: Dependent variable is an indicator for a newborn death within a week of being born. It has been scaled to allow coefficients to be interpretable as $X$ per 1,000 live births. Controls include indicators for male births, multiple births, first births and young mothers (age<18), dummies for mother's level of schooling, an indicator for women who are married or living with a partner, dummies for ethnicity and religion, dummies for the partner's educational attainment, distance to the nearest health facility, wealth quintile dummies, and a rural-urban indicator. Full set of coefficients not shown to conserve space. Each column includes district and year $\mathrm{x}$ month+A24 fixed effects. In Column 5 , we exclude villages with baseline prevalence of 0 or 1 to account for 'floor' and 'ceiling' effects. Column 6 is equivalent to Column 3 except that district fixed effects have been replaced with cluster fixed effects. Post=1 if birth occurs after December 2007. Standard errors in parentheses are clustered at the district level (there are 27 districts). $* * * p<0.01, * * p<0.05, * p<0.1$ ${ }^{1}$ Omitted group is no schooling; ${ }^{2}$ Omitted group is poorest quintile 
Table 9: What was the effect of the ban on newborn deaths (deaths in the first month)?

\begin{tabular}{|c|c|c|c|c|c|c|}
\hline \multirow[b]{2}{*}{ VARIABLES } & \multicolumn{6}{|c|}{ Child death within the first month } \\
\hline & (1) & (2) & (3) & (4) & (5) & (6) \\
\hline \multirow[t]{2}{*}{ High Exposure x Post } & -4.150 & -4.414 & -1.316 & -1.908 & -0.211 & -2.760 \\
\hline & $(4.242)$ & $(4.274)$ & (4.369) & $(4.515)$ & $(4.603)$ & (4.337) \\
\hline \multirow[t]{2}{*}{ High Exposure } & $6.659 * *$ & $6.292^{*}$ & 5.465 & 5.428 & 3.899 & \\
\hline & $(3.142)$ & $(3.395)$ & $(3.472)$ & $(3.531)$ & (3.994) & \\
\hline \multirow[t]{2}{*}{ Post } & & & & -35.98 & -54.18 & -7.293 \\
\hline & & & & $(26.75)$ & $(35.46)$ & $(44.58)$ \\
\hline \multirow[t]{2}{*}{ Male birth } & & $7.415^{* * *}$ & & & & \\
\hline & & $(1.988)$ & & & & \\
\hline \multirow[t]{2}{*}{ First birth } & & $19.33^{* * *}$ & & & & \\
\hline & & $(3.238)$ & & & & \\
\hline \multirow[t]{2}{*}{ Young mother } & & $13.76^{* * *}$ & & & & \\
\hline & & $(4.204)$ & & & & \\
\hline \multirow[t]{2}{*}{ Mother's education: primary school $^{1}$} & & $4.645^{* *}$ & & & & \\
\hline & & $(2.065)$ & & & & \\
\hline \multirow[t]{2}{*}{ Mother's education: secondary school ${ }^{1}$} & & 1.470 & & & & \\
\hline & & $(2.937)$ & & & & \\
\hline \multirow[t]{2}{*}{ Mother's education: tertiary school ${ }^{1}$} & & 8.434 & & & & \\
\hline & & $(8.459)$ & & & & \\
\hline \multirow[t]{2}{*}{ Married or living with partner } & & -0.443 & & & & \\
\hline & & $(2.854)$ & & & & \\
\hline \multirow[t]{2}{*}{ Religion $=$ Christian } & & -5.104 & & & & \\
\hline & & $(8.849)$ & & & & \\
\hline \multirow[t]{2}{*}{ Religion $=$ Muslim } & & -0.806 & & & & \\
\hline & & $(8.888)$ & & & & \\
\hline \multirow[t]{2}{*}{ Spouse's education: primary school ${ }^{1}$} & & -4.315 & & & & \\
\hline & & $(2.971)$ & & & & \\
\hline \multirow[t]{2}{*}{ Spouse's education: secondary school ${ }^{1}$} & & $-13.04 * * *$ & & & & \\
\hline & & (3.468) & & & & \\
\hline \multirow[t]{2}{*}{ Spouse's education: tertiary school ${ }^{1}$} & & $-22.51 * * *$ & & & & \\
\hline & & $(3.406)$ & & & & \\
\hline \multirow[t]{2}{*}{ Wealth quintile $2^{2}$} & & 5.702 & & & & \\
\hline & & $(3.625)$ & & & & \\
\hline \multirow[t]{2}{*}{ Wealth quintile $3^{2}$} & & 4.725 & & & & \\
\hline & & (3.209) & & & & \\
\hline \multirow[t]{2}{*}{ Wealth quintile $4^{2}$} & & 4.719 & & & & \\
\hline & & $(3.396)$ & & & & \\
\hline \multirow[t]{2}{*}{ Wealth quintile $5^{2}$} & & $7.686^{*}$ & & & & \\
\hline & & (4.218) & & & & \\
\hline \multirow[t]{2}{*}{ Rural location } & & 3.706 & & & & \\
\hline & & $(3.262)$ & & & & \\
\hline Distance to health facility & & -0.00941 & & & & \\
\hline
\end{tabular}


(0.377)

\begin{tabular}{lccccccc} 
& & \multicolumn{3}{c}{$208.7^{* *}$} & $231.5^{* *}$ & \\
Constant & $31.90^{* * *}$ & $22.13^{*}$ & $21.72^{*}$ & $*$ & $*$ & 21.07 \\
& $(0.543)$ & $(11.61)$ & $(11.49)$ & $(41.97)$ & $(54.47)$ & $(15.41)$ \\
Controls & & & & & & Yes \\
Controls x Post & No & Yes & Yes & Yes & Yes & Yes \\
District-specific trend & No & No & Yes & Yes & Yes & No \\
Trimmed data & No & No & No & Yes & Yes & No \\
Cluster Fixed Effects & No & No & No & No & Yes & No & Yes \\
& No & No & No & No & & \\
Observations & & & & & & \\
R-squared & 35,246 & 33,748 & 33,748 & 33,748 & 22,317 & 33,748 \\
\hline
\end{tabular}

Notes: Dependent variable is an indicator for a newborn death within a month of being born. It has been scaled to allow coefficients to be interpretable as $X$ per 1,000 live births. Controls include indicators for male births, multiple births, first births and young mothers (age<18), dummies for mother's level of schooling, an indicator for women who are married or living with a partner, dummies for ethnicity and religion, dummies for the partner's educational attainment, distance to the nearest health facility, wealth quintile dummies, and a rural-urban indicator. Full set of coefficients not shown to conserve space. Each column includes district and year $\mathrm{x}$ month fixed effects. In Column 5, we exclude villages with baseline prevalence of 0 or 1 to account for 'floor' and 'ceiling' effects. Column 6 is equivalent to Column 3 except that district fixed effects have been replaced with cluster fixed effects. Post=1 if birth occurs after December 2007. Standard errors in parentheses are clustered at the district level (there are 27 districts). ${ }^{* * *} p<0.01,{ }^{* *} p<0.05,{ }^{*} p<0.1$ ${ }^{1}$ Omitted group is no schooling; ${ }^{2}$ Omitted group is poorest quintile 
Table 10: Effect of the ban on child mortality - Triple difference specification

\begin{tabular}{lccc}
\hline & \multicolumn{3}{c}{ Child death } \\
VARIABLES & $(1)$ & $(2)$ & $(3)$ \\
\hline High Exposure x Post x Treated & & & \\
& $\mathbf{- 1 . 3 2 0}$ & $\mathbf{- 1 . 3 3 2}$ & $\mathbf{3 . 0 0 8}$ \\
High Exposure x Treated & $\mathbf{( 3 . 5 1 8 )}$ & $\mathbf{( 3 . 4 7 4 )}$ & $\mathbf{( 3 . 4 6 8 )}$ \\
& $4.093^{*}$ & $4.051^{*}$ & 2.060 \\
Treated x Post & $(2.122)$ & $(2.132)$ & $(2.457)$ \\
& 1.209 & 1.639 & -2.541 \\
High Exposure x Post & $(2.113)$ & $(2.148)$ & $(2.379)$ \\
& -0.00819 & 0.0151 & -0.502 \\
High Exposure & $(1.552)$ & $(1.538)$ & $(1.672)$ \\
& -0.207 & -0.252 & -0.431 \\
Post & $(1.062)$ & $(1.061)$ & $(1.102)$ \\
& & -9.929 & $-15.05 *$ \\
Treated & & $(7.668)$ & $(8.550)$ \\
Constant & 0.548 & 0.261 & -0.115 \\
& $(8.593)$ & $(8.499)$ & $(8.792)$ \\
& 6.118 & $59.99 * * *$ & $62.21 * * *$ \\
District-specific trend & $(3.688)$ & $(10.73)$ & $(11.59)$ \\
Trimmed data & & & \\
Observations & No & Yes & Yes \\
R-squared & No & No & Yes \\
\hline
\end{tabular}

Notes: Dependent variable is a child death in year $t$. It has been scaled to allow coefficients to be interpretable as $X$ per 1,000 live births. Treated is equal to 1 for newborns and equal to 0 for children aged 2-5 years in year $t$. Each column includes district and year $\mathrm{x}$ month fixed effects, the full set of controls and their interactions with Post and Treated. In Column 3, we exclude villages with baseline prevalence of 0 or 1 to account for 'floor' and 'ceiling' effects. Post=1 if birth occurs after December 2007. Standard errors in parentheses are clustered at the district level (there are 27 districts). ${ }^{* * *} p<0.01,{ }^{* *} p<0.05,{ }^{*} p<0.1$ 
Table 11: Was there an offsetting effect of relative/friend-attended births?

(1)

VARIABLES

Child death within one week

Child death within one month
Relative/friend-attended births
High travel costs

$0.0430 * * *$
$(0.0140)$
-0.00244
$(0.00499)$
-0.00403
$(0.00659)$

(0.00659)
(2) Low travel costs

$N$

Notes: The sample in Column 1 are women who answered 'yes' when asked whether distance was a 'big problem' in accessing medical services. The sample in Column 2 is women who answered 'no'. The estimates are from the regression specification in Column 5 of Tables 7-9. Standard errors in parentheses are clustered at the district level (there are 27 districts). ${ }^{* * *} p<0.01, * * p<0.05,{ }^{*} p<0.1$ 
Table 12: Complier characteristics

\begin{tabular}{lccc}
\hline & $\mathbf{E}(\mathbf{X} \mid \mathbf{D}$ 1i $>\mathbf{D 0 i})$ & $\mathbf{E}(\mathbf{X})$ & Relative likelihood \\
\hline Male birth & 0.509 & 0.500 & 0.9862 \\
First birth & 0.392 & 0.195 & 1.3172 \\
Multiple pregnancy & 0.067 & 0.043 & 1.3241 \\
Young mother & 0.493 & 0.116 & 1.4276 \\
No maternal education & 0.132 & 0.169 & 0.9862 \\
No paternal education & 0.052 & 0.108 & 0.6248 \\
Has partner & 0.812 & 0.869 & 0.9862 \\
Poorest quintile & 0.178 & 0.228 & 0.8345 \\
Lives far from health facility & 0.226 & 0.249 & 1.0483 \\
Rural location & 0.859 & 0.905 & 0.9448 \\
\hline
\end{tabular}

Notes: The mean of each characteristic for compliers are in Column 1; population means are in Column 2, and the relative likelihood that compliers have a given characteristic are in Column 3. Details for how these are computed are in Section 6.5.2. 
Table 13: Indicators used in constructing quality index

1 Does the facility have a theater?

2 Does the facility have an intensive care unit?

3 Does the facility have a pharmacy?

4 Does the facility have trained staff available 24 hours a day?

6 Does this facility offer blood transfusions?

7 Does this facility offer ambulance services?

8 Does this facility offer laboratory services?

9 How many days a week is this facility open (=1 if 7 days)

Notes: We assign each facility a quality score based on these indicators: we score one point for each indicator and sum the scores. 


\begin{tabular}{|c|c|c|c|c|c|c|c|c|c|c|c|c|}
\hline \multirow{2}{*}{$\begin{array}{l}\text { VARIABLES } \\
\text { High Exposure x Post }\end{array}$} & \multicolumn{6}{|c|}{$\begin{array}{c}\text { Nearest health facility is in the top quartile of quality } \\
\text { distribution } \\
\text { Child death within the first week }\end{array}$} & \multicolumn{6}{|c|}{$\begin{array}{l}\text { Nearest health facility is in the bottom three quartiles of } \\
\text { quality distribution } \\
\text { Child death within the first week }\end{array}$} \\
\hline & $\begin{array}{c}-14.70 * * \\
(6.725)\end{array}$ & $\begin{array}{l}-14.32 * \\
(7.100)\end{array}$ & $\begin{array}{l}-12.59 \\
(8.439)\end{array}$ & $\begin{array}{c}-14.42 \\
(8.651)\end{array}$ & $\begin{array}{c}-13.12 \\
(9.448)\end{array}$ & $\begin{array}{c}-12.84 \\
(8.425)\end{array}$ & $\begin{array}{l}-0.679 \\
(4.418)\end{array}$ & $\begin{array}{l}-0.333 \\
(4.586)\end{array}$ & $\begin{array}{c}2.491 \\
(4.633)\end{array}$ & $\begin{array}{c}2.377 \\
(4.656)\end{array}$ & $\begin{array}{c}5.432 \\
(5.253)\end{array}$ & $\begin{array}{c}1.653 \\
(4.420)\end{array}$ \\
\hline High Exposure & $\begin{array}{l}8.537^{*} \\
(4.738)\end{array}$ & $\begin{array}{l}10.96^{*} \\
(5.745)\end{array}$ & $\begin{array}{l}10.44^{*} \\
(6.006)\end{array}$ & $\begin{array}{l}10.61^{*} \\
(5.969)\end{array}$ & $\begin{array}{c}8.673 \\
(6.034)\end{array}$ & & $\begin{array}{c}4.950 \\
(3.185)\end{array}$ & $\begin{array}{c}4.942 \\
(3.470)\end{array}$ & $\begin{array}{c}4.188 \\
(3.489)\end{array}$ & $\begin{array}{c}4.094 \\
(3.549)\end{array}$ & $\begin{array}{c}2.445 \\
(4.092)\end{array}$ & \\
\hline Post & & & & $\begin{array}{c}-26.32 \\
(15.79)\end{array}$ & $\begin{array}{l}-47.46^{*} \\
(24.46)\end{array}$ & $\begin{array}{c}24.64 \\
(46.70)\end{array}$ & & & & $\begin{array}{l}-29.31 \\
(22.08)\end{array}$ & $\begin{array}{l}-29.31 \\
(26.48)\end{array}$ & $\begin{array}{l}-44.60 \\
(27.03)\end{array}$ \\
\hline Constant & $\begin{array}{c}21.16 * * * \\
(0.976)\end{array}$ & $\begin{array}{c}-13.68 \\
(10.40)\end{array}$ & $\begin{array}{l}-17.15 \\
(10.19)\end{array}$ & $\begin{array}{c}66.70 \\
(41.39)\end{array}$ & $\begin{array}{c}103.3^{* *} \\
(48.35)\end{array}$ & $\begin{array}{l}-4.514 \\
(13.77)\end{array}$ & $\begin{array}{c}30.46^{* * *} \\
(0.566)\end{array}$ & $\begin{array}{c}19.42 \\
(12.07)\end{array}$ & $\begin{array}{c}19.71 \\
(11.97)\end{array}$ & $\begin{array}{c}237.3 * * * \\
(35.30)\end{array}$ & $\begin{array}{c}296.6^{* * *} \\
(34.60)\end{array}$ & $\begin{array}{c}7.268 \\
(16.85)\end{array}$ \\
\hline \multirow[t]{2}{*}{ R-squared } & $\begin{array}{l}8,735 \\
0.015\end{array}$ & $\begin{array}{l}8,570 \\
0.023\end{array}$ & $\begin{array}{l}8,570 \\
0.027\end{array}$ & $\begin{array}{l}8,570 \\
0.017\end{array}$ & $\begin{array}{l}4,764 \\
0.023\end{array}$ & $\begin{array}{l}8,570 \\
0.053\end{array}$ & $\begin{array}{c}25,666 \\
0.007\end{array}$ & $\begin{array}{c}25,178 \\
0.012\end{array}$ & $\begin{array}{c}25,178 \\
0.013\end{array}$ & $\begin{array}{c}25,178 \\
0.009\end{array}$ & $\begin{array}{c}17,553 \\
0.010\end{array}$ & $\begin{array}{c}25,178 \\
0.039\end{array}$ \\
\hline & \multicolumn{6}{|c|}{ Child death within the first month } & \multicolumn{6}{|c|}{ Child death within the first month } \\
\hline High Exposure x Post & $\begin{array}{c}-17.33 * * \\
(7.479)\end{array}$ & $\begin{array}{l}-17.02 * * \\
(8.067)\end{array}$ & $\begin{array}{l}-16.00 \\
(10.04)\end{array}$ & $\begin{array}{l}-17.73^{*} \\
(10.19)\end{array}$ & $\begin{array}{l}-12.76 \\
(10.22)\end{array}$ & $\begin{array}{l}-17.69 * \\
(10.14)\end{array}$ & $\begin{array}{l}-1.482 \\
(5.376)\end{array}$ & $\begin{array}{l}-1.899 \\
(5.577)\end{array}$ & $\begin{array}{c}1.340 \\
(5.666)\end{array}$ & $\begin{array}{c}1.459 \\
(5.668)\end{array}$ & $\begin{array}{c}2.604 \\
(6.127)\end{array}$ & $\begin{array}{l}-0.0690 \\
(5.658)\end{array}$ \\
\hline High Exposure & $\begin{array}{c}9.091 \\
(5.670)\end{array}$ & $\begin{array}{c}11.65^{*} \\
(6.633)\end{array}$ & $\begin{array}{c}11.25 \\
(7.109)\end{array}$ & $\begin{array}{c}11.64 \\
(7.070)\end{array}$ & $\begin{array}{c}8.405 \\
(6.658)\end{array}$ & & $\begin{array}{c}6.391 \\
(3.934)\end{array}$ & $\begin{array}{c}5.658 \\
(4.172)\end{array}$ & $\begin{array}{c}4.839 \\
(4.254)\end{array}$ & $\begin{array}{c}4.584 \\
(4.288)\end{array}$ & $\begin{array}{c}3.835 \\
(4.869)\end{array}$ & \\
\hline Post & & & & $\begin{array}{c}-33.89 \\
(34.30)\end{array}$ & $\begin{array}{l}-45.00 * \\
(25.51)\end{array}$ & $\begin{array}{c}60.43 \\
(89.20)\end{array}$ & & & & $\begin{array}{l}-41.40 \\
(34.54)\end{array}$ & $\begin{array}{l}-62.67 \\
(45.67)\end{array}$ & $\begin{array}{l}-60.54 \\
(35.73)\end{array}$ \\
\hline Constant & $\begin{array}{c}31.91 * * * \\
(1.009)\end{array}$ & $\begin{array}{c}13.77 \\
(25.26)\end{array}$ & $\begin{array}{c}11.46 \\
(26.43)\end{array}$ & $\begin{array}{c}122.1 * * \\
(51.73)\end{array}$ & $\begin{array}{c}125.2 \\
(77.49)\end{array}$ & $\begin{array}{c}29.74 \\
(36.08)\end{array}$ & $\begin{array}{c}36.17^{* * *} \\
(0.599)\end{array}$ & $\begin{array}{c}23.61 \\
(13.94)\end{array}$ & $\begin{array}{c}23.38 \\
(13.69)\end{array}$ & $\begin{array}{c}227.9 * * * \\
(37.19)\end{array}$ & $\begin{array}{c}351.2^{* * *} \\
(41.04)\end{array}$ & $\begin{array}{c}19.69 \\
(18.61)\end{array}$ \\
\hline Controls & No & Yes & Yes & Yes & Yes & Yes & No & Yes & Yes & Yes & Yes & Yes \\
\hline Controls $x$ Post & No & No & Yes & Yes & Yes & Yes & No & No & Yes & Yes & Yes & Yes \\
\hline District-specific trend & No & No & No & Yes & Yes & No & No & No & No & Yes & Yes & No \\
\hline Trimmed data & No & No & No & No & Yes & No & No & No & No & No & Yes & No \\
\hline Cluster Fixed Effects & No & No & No & No & No & Yes & No & No & No & No & No & Yes \\
\hline Observations & 8,735 & 8,570 & 8,570 & 8,570 & 4,764 & 8,570 & 25,666 & 25,178 & 25,178 & 25,178 & 17,553 & 25,178 \\
\hline R-squared & 0.019 & 0.028 & 0.030 & 0.019 & 0.024 & 0.054 & 0.007 & 0.013 & 0.014 & 0.011 & 0.013 & 0.039 \\
\hline
\end{tabular}


Notes: Coefficients have been scaled to allow them to be interpreted as $X$ per 1,000 live births. The sample in Panel A (left) consists of births to households with access to high- quality formal care (equal to one if the nearest health facility is within the top quartile of the quality distribution) while the sample in Panel B (right) consists of births to households where the nearest health facility is in the bottom three quartiles of the quality distribution. The dependent variables are shown at the top of each set of results. Controls include indicators for male births, multiple births, first births and young mothers (age<18), dummies for mother's level of schooling, an indicator for women who are married or living with a partner, dummies for ethnicity and religion, dummies for the partner's educational attainment, distance to the nearest health facility, wealth quintile dummies, and a rural-urban indicator. Each column includes district and year x month fixed effects. In Column 5 , we exclude villages with baseline prevalence of 0 or 1 to account for 'floor' and 'ceiling' effects. Column 6 is equivalent to Column 3 except that district fixed effects have been replaced with cluster fixed effects. Post=1 if birth occurs after December 2007. Standard errors in parentheses are clustered at the district level (there are 27 districts). ${ }^{* * *} p<0.01,{ }^{* *} p<0.05,{ }^{*} p<0.1$ 
Appendix Tables 
Table A.1: Robustness check - changing the mortality recall window

\begin{tabular}{|c|c|c|c|c|}
\hline \multirow[b]{2}{*}{ VARIABLES } & \multicolumn{2}{|c|}{ Births in the last 5 years } & \multicolumn{2}{|c|}{ Births in the last 20 years } \\
\hline & $\begin{array}{l}\text { Child death in the } \\
\text { first week }\end{array}$ & $\begin{array}{l}\text { Child death in the } \\
\text { first month }\end{array}$ & $\begin{array}{l}\text { Child death in } \\
\text { the first week }\end{array}$ & $\begin{array}{l}\text { Child death in } \\
\text { the first month }\end{array}$ \\
\hline \multirow{2}{*}{ High Exposure $x$ Post } & 3.209 & -1.666 & 3.938 & 1.493 \\
\hline & (4.139) & (4.274) & (3.178) & $(3.564)$ \\
\hline \multirow[t]{2}{*}{ High Exposure } & 1.502 & 5.216 & 1.626 & 2.828 \\
\hline & (3.635) & (3.687) & (2.355) & $(2.900)$ \\
\hline \multirow[t]{2}{*}{ Post } & -14.61 & -37.67 & $-35.30 *$ & -47.58 \\
\hline & $(22.26)$ & $(36.02)$ & $(19.22)$ & (32.89) \\
\hline \multirow[t]{2}{*}{ Constant } & $387.5^{* * *}$ & $630.3^{* * *}$ & $54.26 * * *$ & $38.02 *$ \\
\hline & $(112.8)$ & $(150.6)$ & $(13.06)$ & (19.52) \\
\hline Observations & 13,286 & 13,286 & 37,183 & 37,183 \\
\hline R-squared & 0.014 & 0.015 & 0.008 & 0.011 \\
\hline
\end{tabular}

Notes: In Panel A (left) we restrict the sample to births in the last five years, and in Panel B (right) the sample consists of all births within the last 20 years. The dependent variables are shown at the top of each column. The results correspond to the specifications in Column 5 of Tables 8 and 9. Again coefficients are scaled to allow interpretation as $X$ per 1,000 live births. Each column includes district and year $\mathrm{x}$ month fixed effects, the full set of controls and their interactions with Post and villages with baseline prevalence of 0 or 1 are excluded. Standard errors in parentheses are clustered at the district level (there are 27 districts). ${ }^{* * *} p<0.01,{ }^{* *} p<0.05, * p<0.1$ 
Table A.2: Robustness check - Exposure is continuous

\begin{tabular}{|c|c|c|c|c|c|c|}
\hline VARIABLES & $\begin{array}{c}\text { (1) } \\
\text { Informal birth } \\
\text { attendant }\end{array}$ & $\begin{array}{c}\text { (2) } \\
\text { Formal birth } \\
\text { attendant }\end{array}$ & $\begin{array}{c}\text { (3) } \\
\text { Relative/friend } \\
\text { attended birth }\end{array}$ & $\begin{array}{c}\text { (4) } \\
\text { Unattended } \\
\text { birth }\end{array}$ & $\begin{array}{c}\text { (5) } \\
\text { Child death } \\
\text { within one week }\end{array}$ & $\begin{array}{c}(6) \\
\text { Child death within } \\
\text { one month }\end{array}$ \\
\hline Baseline prevalence $\mathrm{x}$ Post & $\begin{array}{c}-0.538 * * * \\
(0.0496)\end{array}$ & $\begin{array}{c}0.376 * * * \\
(0.0437)\end{array}$ & $\begin{array}{c}0.144 * * * \\
(0.0336)\end{array}$ & $\begin{array}{c}0.0101 \\
(0.0140)\end{array}$ & $\begin{array}{l}-0.648 \\
(12.13)\end{array}$ & $\begin{array}{l}-7.086 \\
(13.16)\end{array}$ \\
\hline Baseline prevalence & $\begin{array}{l}0.967 * * * \\
(0.00933)\end{array}$ & $\begin{array}{c}-0.751 * * * \\
(0.0384)\end{array}$ & $\begin{array}{c}-0.170 * * * \\
(0.0362)\end{array}$ & $\begin{array}{l}-0.0288^{*} \\
(0.0158)\end{array}$ & $\begin{array}{l}10.65 \\
(9.830)\end{array}$ & $\begin{array}{c}15.93 \\
(11.35)\end{array}$ \\
\hline Post & $\begin{array}{c}0.0239 \\
(0.0779)\end{array}$ & $\begin{array}{c}0.0687 \\
(0.0846)\end{array}$ & $\begin{array}{l}-0.0602 \\
(0.0816)\end{array}$ & $\begin{array}{l}0.00606 \\
(0.0577)\end{array}$ & $\begin{array}{l}-32.70 \\
(21.55)\end{array}$ & $\begin{array}{l}-52.12 \\
(35.88)\end{array}$ \\
\hline Constant & $\begin{array}{c}3.527^{* * *} \\
(0.434)\end{array}$ & $\begin{array}{c}-2.426 * * * \\
(0.477)\end{array}$ & $\begin{array}{c}0.235 \\
(0.333)\end{array}$ & $\begin{array}{l}-0.229 \\
(0.198)\end{array}$ & $\begin{array}{c}140.0 * * * \\
(35.79)\end{array}$ & $\begin{array}{c}231.0 * * * \\
(54.82)\end{array}$ \\
\hline $\begin{array}{l}\text { Observations } \\
\text { R-squared }\end{array}$ & $\begin{array}{c}12,491 \\
0.143\end{array}$ & $\begin{array}{c}12,491 \\
0.118\end{array}$ & $\begin{array}{c}12,491 \\
0.043\end{array}$ & $\begin{array}{c}12,491 \\
0.039\end{array}$ & $\begin{array}{c}22,317 \\
0.009\end{array}$ & $\begin{array}{c}22,317 \\
0.012\end{array}$ \\
\hline
\end{tabular}

Notes: The dependent variables are shown at the top of each column. Baseline prevalence is the village-level historical rate of informal birth attendant use. Post $=1$ if birth occurs after December 2007. The estimates are from the regression specifications in Column 5 of Tables 5-9. Coefficients in columns 5 and 6 have been scaled to allow them to be interpreted as $X$ per 1,000 live births. Each column includes district and year $\mathrm{x}$ month fixed effects, the full set of controls and their interactions with Post and villages with baseline prevalence of 0 or 1 are excluded. Standard errors in parentheses are clustered at the district level (there are 27 districts). ${ }^{* * *} p<0.01,{ }^{* *} p<0.05,{ }^{*} p<0.1$ 
Table A.3: Are results robust to inclusion of stillbirths

\begin{tabular}{|c|c|c|c|c|c|c|}
\hline \multirow[b]{2}{*}{ VARIABLES } & \multicolumn{6}{|c|}{ Perinatal mortality } \\
\hline & $(1)$ & $(2)$ & (3) & $(4)$ & (5) & $(6)$ \\
\hline \multirow[t]{2}{*}{ High Exposure x Post } & -3.890 & -3.803 & 0.953 & 0.304 & 2.708 & 1.134 \\
\hline & $(4.042)$ & $(3.920)$ & $(4.513)$ & $(4.427)$ & $(4.911)$ & (4.435) \\
\hline \multirow[t]{2}{*}{ High Exposure } & $7.557 * * *$ & $5.478 * *$ & 4.156 & 3.984 & 1.198 & \\
\hline & $(2.216)$ & $(2.510)$ & $(2.638)$ & $(2.667)$ & $(3.415)$ & \\
\hline \multirow[t]{2}{*}{ Post } & & & & $-41.52 * *$ & $-51.90 * *$ & -40.51 \\
\hline & & & & $(17.93)$ & $(23.82)$ & (31.96) \\
\hline \multirow[t]{2}{*}{ Constant } & $32.73 * * *$ & 8.971 & 7.987 & $170.6^{* * *}$ & $90.91 * * *$ & 19.22 \\
\hline & $(0.428)$ & $(10.73)$ & $(10.82)$ & $(34.55)$ & (30.19) & $(19.82)$ \\
\hline Controls & No & Yes & Yes & Yes & Yes & Yes \\
\hline Controls $\mathrm{x}$ Post & No & No & Yes & Yes & Yes & Yes \\
\hline District-specific trend & No & No & No & Yes & Yes & No \\
\hline Trimmed data & No & No & No & No & Yes & No \\
\hline Cluster Fixed Effects & No & No & No & No & No & Yes \\
\hline Observations & 35,246 & 33,748 & 33,748 & 33,748 & 22,317 & 33,748 \\
\hline R-squared & 0.005 & 0.011 & 0.012 & 0.009 & 0.010 & 0.045 \\
\hline
\end{tabular}

Notes: Dependent variable is an indicator for a stillbirth or a newborn death within the first week. Coefficients have been scaled to allow them to be interpreted as $X$ per 1,000 live births. Controls include indicators for male births, multiple births, first births and young mothers (age $<18$ ), dummies for mother's level of schooling, an indicator for women who are married or living with a partner, dummies for ethnicity and religion, dummies for the partner's educational attainment, distance to the nearest health facility, wealth quintile dummies, and a rural-urban indicator. Each column includes district and year $x$ month fixed effects. In Column 5, we exclude villages with baseline prevalence of 0 or 1 to account for 'floor' and 'ceiling' effects. Column 6 is equivalent to Column 3 except that district fixed effects have been replaced with cluster fixed effects. Post=1 if birth occurs after December 2007. Standard errors in parentheses are clustered at the district level (there are 27 districts). ${ }^{* * *} p<0.01,{ }^{* *} p<0.05, * p<0.1$ 
Table A.4: Did the ban change patterns of prenatal care?

\begin{tabular}{|c|c|c|c|c|c|c|c|c|c|}
\hline \multirow[b]{2}{*}{ VARIABLES } & (1) & (2) & (3) & (4) & (5) & (6) & (7) & (8) & (9) \\
\hline & \multicolumn{3}{|c|}{ Number of prenatal visits } & \multicolumn{3}{|c|}{ Provider is a doctor/clinical officer } & \multicolumn{3}{|c|}{ Provider is nurse/midwife } \\
\hline \multirow[t]{2}{*}{ High Exposure x Post } & -0.020 & -0.025 & -0.013 & -0.0049 & -0.008 & -0.0013 & -0.015 & -0.011 & -0.010 \\
\hline & $(0.080)$ & $(0.084)$ & $(0.094)$ & $(0.014)$ & $(0.015)$ & $(0.017)$ & $(0.018)$ & $(0.019)$ & $(0.019)$ \\
\hline \multirow[t]{2}{*}{ High Exposure } & 0.0316 & 0.0405 & 0.0335 & 0.00133 & 0.00377 & -0.00216 & -0.00303 & -0.00644 & 0.00253 \\
\hline & $(0.069)$ & $(0.072)$ & $(0.084)$ & $(0.015)$ & $(0.016)$ & $(0.017)$ & $(0.019)$ & $(0.020)$ & $(0.020)$ \\
\hline \multirow[t]{2}{*}{ Post } & & 0.483 & 0.449 & & -0.104 & -0.0381 & & 0.0429 & -0.0374 \\
\hline & & (0.349) & $(0.375)$ & & $(0.086)$ & $(0.097)$ & & $(0.097)$ & $(0.118)$ \\
\hline \multirow{2}{*}{ Constant } & $3.405^{* * *}$ & $12.09 * * *$ & $11.53 * * *$ & -0.0405 & -0.0145 & -0.0379 & $0.951 * * *$ & 0.609 & 0.188 \\
\hline & $(0.168)$ & $(1.441)$ & $(2.234)$ & $(0.034)$ & $(0.359)$ & $(0.448)$ & $(0.058)$ & $(0.430)$ & $(0.460)$ \\
\hline District-specific trend & No & Yes & Yes & No & Yes & Yes & No & Yes & Yes \\
\hline Trimmed data & No & No & Yes & No & No & Yes & No & No & Yes \\
\hline
\end{tabular}

Notes: The sample sizes are smaller because information about prenatal care is only collected for the most recent birth. Each column includes district and year $\mathrm{x}$ month fixed effects, the full set of controls and their interactions with Post. In Columns 3, 6, and 9 we exclude villages with baseline prevalence of 0 or 1 to account for 'floor' and 'ceiling' effects. Post=1 if birth occurs after December 2007. Standard errors in parentheses are clustered at the district level (there are 27 districts). $* * * \mathrm{p}<0.01, * * \mathrm{p}<0.05, * \mathrm{p}<0.1$ 
Table A.5: Quadruple difference specification (early neonatal deaths)

\begin{tabular}{|c|c|c|c|c|c|c|}
\hline \multirow{2}{*}{$\begin{array}{l}\text { VARIABLES } \\
\text { High Exposure } x \text { Post } x \text { Treated }\end{array}$} & \multicolumn{3}{|c|}{$\begin{array}{c}\text { Nearest health facility is in the } \\
\text { top quartile of quality } \\
\text { distribution }\end{array}$} & \multicolumn{3}{|c|}{$\begin{array}{c}\text { Nearest health facility is in the } \\
\text { bottom three quartiles of quality } \\
\text { distribution }\end{array}$} \\
\hline & $-12.25^{*}$ & $-12.31 *$ & -8.791 & 1.547 & 1.587 & 5.917 \\
\hline & $(6.648)$ & $(6.722)$ & $(6.965)$ & $(4.213)$ & $(4.215)$ & $(4.312)$ \\
\hline \multirow[t]{2}{*}{ High Exposure $x$ Treated } & 5.219 & 4.887 & 2.878 & 4.474 & 4.379 & 2.489 \\
\hline & (3.529) & $(3.621)$ & (3.742) & $(2.641)$ & $(2.653)$ & $(3.127)$ \\
\hline \multirow[t]{2}{*}{ Treated $x$ Post } & 0.631 & 2.155 & -1.518 & 1.549 & 1.481 & -2.701 \\
\hline & (3.555) & $(3.760)$ & $(4.300)$ & $(2.785)$ & $(2.785)$ & (3.015) \\
\hline \multirow[t]{2}{*}{ High Exposure x Post } & 1.637 & 2.081 & 3.251 & -0.675 & -0.529 & -1.278 \\
\hline & $(2.693)$ & $(2.909)$ & (3.208) & $(1.697)$ & $(1.663)$ & $(1.794)$ \\
\hline \multirow[t]{2}{*}{ High Exposure } & 0.464 & 0.376 & -0.593 & -0.395 & -0.453 & -0.452 \\
\hline & $(1.623)$ & $(1.548)$ & $(1.698)$ & $(1.162)$ & (1.153) & $(1.147)$ \\
\hline \multirow[t]{2}{*}{ Post } & & $-19.94 * *$ & $-16.45^{*}$ & & -9.797 & -15.44 \\
\hline & & (7.639) & $(8.971)$ & & $(10.49)$ & $(10.94)$ \\
\hline \multirow[t]{2}{*}{ Treated } & $-23.76^{*}$ & $-22.96 *$ & -8.189 & 5.281 & 4.782 & 0.813 \\
\hline & $(13.03)$ & $(13.20)$ & (9.667) & (10.19) & (10.05) & (10.39) \\
\hline \multirow[t]{2}{*}{ Constant } & 11.87 & $51.22 * * *$ & $48.28 * * *$ & $9.967 * * *$ & $82.92 * * *$ & $105.5^{* * *}$ \\
\hline & $(9.106)$ & $(13.88)$ & $(10.08)$ & $(3.542)$ & $(10.75)$ & $(9.456)$ \\
\hline District-specific trend & No & Yes & Yes & No & Yes & Yes \\
\hline Trimmed data & No & No & Yes & No & No & Yes \\
\hline Observations & 31,241 & 31,241 & 17,031 & 91,060 & 91,060 & 62,565 \\
\hline R-squared & 0.015 & 0.011 & 0.015 & 0.009 & 0.007 & 0.008 \\
\hline
\end{tabular}

Notes: The sample in Panel A (left) consists of births to households with access to high-quality formal care (equal to one if the nearest health facility is within the top quartile of the quality distribution) while the sample in Panel $B$ (right) consists of births to households where the nearest health facility is in the bottom three quartiles of the quality distribution. Treated is equal to 1 for newborns and equal to 0 for children aged 2-5 years in year $t$. Dependent variable is a child death in year $t$. Coefficients have been scaled to allow them to be interpreted as $X$ per 1,000 live births. Each column includes district and year $\mathrm{x}$ month fixed effects, the full set of controls and their interactions with Post and Treated. In Column 3, we exclude villages with baseline prevalence of 0 or 1 to account for 'floor' and 'ceiling' effects. Post=1 if birth occurs after December 2007. Standard errors in parentheses are clustered at the district level (there are 27 districts). ${ }^{* * *} p<0.01,{ }^{* *} p<0.05,{ }^{*} p<0.1$ 
Table A.6: Robustness check: Differential trends in observables (Integrated Household Survey 2004/2010)

\begin{tabular}{|c|c|c|c|c|c|c|c|}
\hline VARIABLES & $\begin{array}{l}\text { Average age for } \\
\text { grade (of school age } \\
\text { kids) } \\
(1)\end{array}$ & $\begin{array}{c}\text { Average } \\
\text { completed } \\
\text { schooling } \\
\text { (2) }\end{array}$ & $\begin{array}{c}\text { Average } \\
\text { employment rate } \\
\text { (within } \mathrm{HH} \text { ) } \\
\text { (3) }\end{array}$ & $\begin{array}{c}\text { Average salary } \\
\text { (within } \mathrm{HH} \text { ) } \\
\text { (4) }\end{array}$ & $\begin{array}{l}\text { Household } \\
\text { head } \\
\text { education } \\
\text { (5) }\end{array}$ & $\begin{array}{l}\text { Household } \\
\text { head } \\
\text { employed } \\
(6)\end{array}$ & $\begin{array}{c}\mathrm{HHH} \\
\text { average } \\
\text { salary } \\
\text { (7) }\end{array}$ \\
\hline High Exposure X Post & $\begin{array}{c}6.429 \\
(18.64)\end{array}$ & $\begin{array}{c}3.065 \\
(2.119)\end{array}$ & $\begin{array}{c}0.185 \\
(0.165)\end{array}$ & $\begin{array}{c}1,740 \\
(4,022)\end{array}$ & $\begin{array}{c}3.521 \\
(2.745)\end{array}$ & $\begin{array}{c}0.257 \\
(0.239)\end{array}$ & $\begin{array}{c}2,612 \\
(6,747)\end{array}$ \\
\hline High Exposure & $\begin{array}{l}-25.19 \\
(14.88)\end{array}$ & $\begin{array}{l}-3.518^{*} \\
(1.881)\end{array}$ & $\begin{array}{l}-0.184 \\
(0.111)\end{array}$ & $\begin{array}{l}-2,118 \\
(1,334)\end{array}$ & $\begin{array}{l}-4.012 * \\
(2.334)\end{array}$ & $\begin{array}{l}-0.259 \\
(0.158)\end{array}$ & $\begin{array}{l}-3,594 \\
(2,247)\end{array}$ \\
\hline Post & $\begin{array}{l}-3.502 \\
(5.015)\end{array}$ & $\begin{array}{l}-0.171 \\
(0.674)\end{array}$ & $\begin{array}{l}-0.0758 \\
(0.0531)\end{array}$ & $\begin{array}{c}1,619 \\
(1,263)\end{array}$ & $\begin{array}{c}0.192 \\
(0.873)\end{array}$ & $\begin{array}{l}-0.0948 \\
(0.0749)\end{array}$ & $\begin{array}{c}2,944 \\
(2,156)\end{array}$ \\
\hline Constant & $\begin{array}{c}62.07^{* * *} \\
(4.753)\end{array}$ & $\begin{array}{c}4.981^{* * *} \\
(0.668)\end{array}$ & $\begin{array}{c}0.218^{* * *} \\
(0.0398)\end{array}$ & $\begin{array}{c}1,480 * * \\
(574.1)\end{array}$ & $\begin{array}{c}5.899 * * * \\
(0.826)\end{array}$ & $\begin{array}{c}0.315^{* * *} \\
(0.0571)\end{array}$ & $\begin{array}{c}2,419 * * \\
(962.5)\end{array}$ \\
\hline Observations & 16,579 & 23,549 & 23,373 & 23,363 & 23,487 & 23,270 & 23,224 \\
\hline R-squared & 0.004 & 0.018 & 0.006 & 0.004 & 0.019 & 0.004 & 0.005 \\
\hline
\end{tabular}

Notes: The dependent variables are shown at the top of each column. High exposure is defined at the district-rural/urban level based on informal birth attendant use in the MDHS pre-ban. Post = 1 if data comes from the 2010 survey wave (post-ban); and 0 if it comes from the 2004 survey wave (pre ban). Standard errors in parentheses are clustered at the district level. ${ }^{* * *} p<0.01,{ }^{* *} p<0.05, * p<0.1$ 
Table A.7: Differential Shocks (Integrated Household Survey 2004/2010)

\begin{tabular}{|c|c|c|c|c|c|c|c|}
\hline VARIABLES & $\begin{array}{c}\text { Drought/ Irregular } \\
\text { Rains and Floods/ } \\
\text { Landslides } \\
\text { (1) }\end{array}$ & $\begin{array}{l}\text { Unusually high } \\
\text { level of crop } \\
\text { pests or disease } \\
\text { (2) }\end{array}$ & $\begin{array}{l}\text { Unusually high } \\
\text { level of livestock } \\
\text { disease } \\
\text { (3) }\end{array}$ & $\begin{array}{l}\text { Unusually low } \\
\text { prices for } \\
\text { agricultural output } \\
\text { (4) }\end{array}$ & $\begin{array}{l}\text { Unusually } \\
\text { high prices } \\
\text { for food } \\
\text { (5) }\end{array}$ & $\begin{array}{l}\text { Death of } \\
\text { income } \\
\text { earner } \\
(6)\end{array}$ & $\begin{array}{c}\text { Theft of } \\
\text { valuables/assets } \\
\text { (7) }\end{array}$ \\
\hline \multirow[t]{2}{*}{ High Exposure X Post } & $0.994^{*}$ & -0.0701 & 0.0609 & 0.469 & 0.464 & $0.125^{*}$ & 0.131 \\
\hline & -0.532 & -0.247 & -0.315 & -0.432 & -0.383 & -0.0638 & -0.189 \\
\hline \multirow[t]{2}{*}{ High Exposure } & -0.195 & -0.0998 & -0.214 & $-0.986 * * *$ & -0.509 & $-0.124^{*}$ & -0.156 \\
\hline & -0.394 & -0.219 & -0.279 & -0.351 & -0.31 & -0.0666 & -0.173 \\
\hline \multirow[t]{2}{*}{ Post } & -0.0651 & $0.204^{* * *}$ & $0.270 * * *$ & 0.133 & $0.390 * * *$ & $0.0419 *$ & $0.114^{* *}$ \\
\hline & -0.156 & -0.0696 & -0.0929 & -0.115 & -0.107 & -0.0211 & -0.048 \\
\hline \multirow[t]{2}{*}{ Constant } & $1.427^{* * *}$ & $1.788 * * *$ & $1.707^{* * *}$ & $1.870 * * *$ & $1.355^{* * *}$ & $1.946 * * *$ & $1.834^{* * *}$ \\
\hline & -0.124 & -0.0721 & -0.0925 & -0.111 & -0.104 & -0.0217 & -0.0451 \\
\hline Observations & 23548 & 23548 & 23548 & 23548 & 23549 & 23549 & 23548 \\
\hline R-squared & 0.06 & 0.072 & 0.129 & 0.133 & 0.264 & 0.032 & 0.05 \\
\hline
\end{tabular}

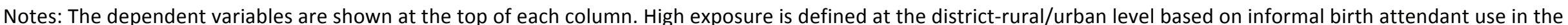

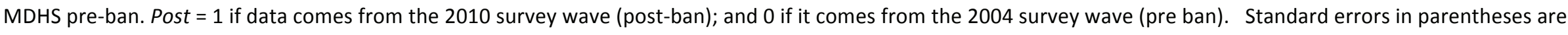
clustered at the district level. ${ }^{* * *} p<0.01,{ }^{* *} p<0.05,{ }^{*} p<0.1$ 